\title{
An Assessment of Atmospheric and Meteorological Factors Regulating Red Sea Phytoplankton Growth
}

\author{
Wenzhao Li ${ }^{1}$, Hesham El-Askary ${ }^{2,3,4, *(1)}$, Mohamed A. Qurban ${ }^{5,6}$, Emmanouil Proestakis ${ }^{7,8}$, \\ Michael J. Garay ${ }^{9}{ }^{(0)}$, Olga V. Kalashnikova ${ }^{9}{ }^{(0)}$, Vassilis Amiridis ${ }^{7}$, Antonis Gkikas ${ }^{7}$ (i), \\ Eleni Marinou ${ }^{7}$ (D), Thomas Piechota ${ }^{3}$ and K. P. Manikandan ${ }^{5}$ \\ 1 Computational and Data Sciences Graduate Program, Schmid College of Science and Technology, \\ Chapman University, Orange, CA 92866, USA; li276@mail.chapman.edu \\ 2 Center of Excellence in Earth Systems Modeling \& Observations, Chapman University, Orange, \\ CA 92866, USA \\ 3 Schmid College of Science and Technology, Chapman University, Orange, CA 92866, USA; \\ piechota@chapman.edu \\ 4 Department of Environmental Sciences, Faculty of Science, Alexandria University, Moharem Bek, \\ Alexandria 21522, Egypt \\ 5 Center for Environment and Water, The Research Institute, King Fahd University of Petroleum and \\ Minerals (KFUPM), Dhahran 31261, Saudi Arabia; mqurban@kfupm.edu.sa (M.A.Q.); \\ manikand@kfupm.edu.sa (K.P.M.) \\ 6 Geosciences Department, The College of Petroleum Engineering \& Geosciences, King Fahd University of \\ Petroleum and Minerals (KFUPM), Dhahran 31261, Saudi Arabia \\ 7 IAASARS, National Observatory of Athens, 15236 Athens, Greece; proestakis@noa.gr (E.P.); \\ vamoir@noa.gr (V.A.); agkikas@noa.gr (A.G.); elmarinou@noa.gr (E.M.) \\ 8 Laboratory of Atmospheric Physics, Department of Physics, University of Patras, 26500 Patras, Greece \\ 9 Jet Propulsion Laboratory, California Institute of Technology, Pasadena, CA 91109, USA; \\ michael.j.garay@jpl.nasa.gov (M.J.G.); olga.kalashnikova@jpl.nasa.gov (O.V.K.) \\ * Correspondence: elaskary@chapman.edu; Tel.: +1-714-289-2053
}

Received: 5 April 2018; Accepted: 23 April 2018; Published: 26 April 2018

\begin{abstract}
This study considers the various factors that regulate nutrients supply in the Red Sea. Multi-sensor observation and reanalysis datasets are used to examine the relationships among dust deposition, sea surface temperature (SST), and wind speed, as they may contribute to anomalous phytoplankton blooms, through time-series and correlation analyses. A positive correlation was found at 0-3 months lag between chlorophyll- $a(\mathrm{Chl}-a)$ anomalies and dust anomalies over the Red Sea regions. Dust deposition process was further examined with dust aerosols' vertical distribution using satellite lidar data. Conversely, a negative correlation was found at $0-3$ months lag between SST anomalies and Chl- $a$ that was particularly strong in the southern Red Sea during summertime. The negative relationship between SST and phytoplankton is also evident in the continuously low levels of Chl-a during 2015 to 2016, which were the warmest years in the region on record. The overall positive correlation between wind speed and Chl- $a$ relate to the nutritious water supply from the Gulf of Aden to the southern Red Sea and the vertical mixing encountered in the northern part. Ocean Color Climate Change Initiative (OC-CCI) dataset experience some temporal inconsistencies due to the inclusion of different datasets. We addressed those issues in our analysis with a valid interpretation of these complex relationships.
\end{abstract}

Keywords: Red Sea; MISR; CALIPSO; OC-CCI; chlorophyll- $a$; dust; SST; wind 


\section{Introduction}

There has been much recent scientific interest in ocean color observations and biological productivity issues in the Red Sea region [1-19]. The Red Sea is surrounded by deserts and other arid land and has no river inflow or stream sources. Its high evaporation rate $(>210 \mathrm{~cm} / \mathrm{yr})$ [20] and low precipitation rate $(<100 \mathrm{~mm} / \mathrm{yr})[21,22]$ results in the Red Sea having the highest salinity of any major tropical oceanic basin [20]. Furthermore, the region is well-known for its extremely high biodiversity, with more than 300 species of coral and 1400 species of fish [23,24]. Fisheries are economically important to this area, as over 100,000 tons of fish are reportedly caught each year [25]. The high temperature and salinity of the water also make the Red Sea an important natural laboratory for understanding the effects of climate change, especially on coral reefs [26-28].

Overall, the Red Sea is considered to be oligotrophic, as its surface waters are deficient in several important nutrients, including nitrate, ammonium, phosphate, and silicate, resulting in low levels of chlorophyll- $a(\mathrm{Chl}-a)\left(<2.6 \mathrm{mg} / \mathrm{m}^{3}\right)$ [4]. However, the basin has a significant north-south gradient in nutrient content that is regulated by the meridional flow [14], and a distinct seasonality with maximum surface water $\mathrm{Chl}-a$ concentrations that are seen during the winter time, and minimum concentrations during the summer [3]. Recent studies using both in situ and satellite observations have also identified regions with higher Chl- $a$ concentrations and nutrient levels than the traditional oligotrophic threshold of $2.6 \mathrm{mg} / \mathrm{m}^{3}[3,4,11,12]$. Locally elevated levels of Chl- $a$ and surface nutrients have been attributed to interactions among oceanic gyres, particularly in the southern portion of the Red Sea $[14,17,19]$, as well as aerial deposition of micro-nutrients, for example, iron (Fe), by wind-blown dust [29].

In an attempt to better understand the relationships among oceanic circulation and atmospheric deposition on Chl- $a$ amounts and nutrient levels in the Red Sea, a recent study examined an anomalously high Chl- $a$ event $\left(>2 \mathrm{mg} / \mathrm{m}^{3}\right)$ that occurred in June 2015 in the South Central Red Sea $\left(17.5^{\circ}\right.$ to $22^{\circ} \mathrm{N}, 37^{\circ}$ to $\left.42^{\circ} \mathrm{E}\right)$ [19]. The analysis suggested that a combination of factors contribute to anomalous phytoplankton events in this portion of the Red Sea basin. These factors include the horizontal transfer of upwelling water through eddy circulation and possible mineral fertilization from atmospheric dust deposition. Notably, a lag correlation analysis revealed a statistically significant two-month positive lag correlation between dust anomalies and Chl- $a$ anomalies using the MODIS-Aqua dataset. A similarly significant two-month negative lag correlation was identified between sea surface temperature (SST) anomalies and Chl- $a$ anomalies [19].

In this study, we further explore the relationships between Chl- $a$ and other potentially important environmental factors in the Red Sea region, including dust aerosol optical depth (DAOD), SST, and wind speed for the period from September 1997 to December 2016. The role of dust is further elucidated through examination of dust sources, dust properties, and the vertical profile of dust in the region.

\section{Materials and Methods}

\subsection{Materials}

\subsubsection{Ocean Color Climate Change Initiative (OC-CCI) Chlorophyll- $a$ Data}

In this study the Ocean Color Climate Change Initiative (OC-CCI) Level-3 Chl- $a$ dataset version 3.1 at $4 \mathrm{~km}$ resolution is used, which extends from September 1997 to December 2016. The OC-CCI dataset is produced by the European Space Agency (ESA) and it merges Chl-a retrievals from the Sea-viewing Wide Field-of-view Sensor (SeaWiFS); the MODerate resolution Imaging Spectroradiometer (MODIS) on the Aqua satellite [30]; the MEdium Resolution Imaging Spectrometer (MERIS), which flew on Envisat-1; and, the Visible Infrared Imaging Radiometer Suite (VIIRS), which flies on the Suomi National Polar-orbiting Partnership (NPP) satellite [31]. Critical steps for achieving data consistency within the OC-CCI dataset include band-shifting and empirical bias correction to match MERIS, MODIS, and VIIRS data with SeaWiFS, and then merging the datasets together to compute uncertainty estimates 
per pixel [31-33]. The OC-CCI dataset has been widely used to address ocean related processes using various optical parameters [18,31,33-36]. For the Red Sea region, in particular, the OC-CCI dataset has been demonstrated to have good consistency with in situ observations along with substantially improved coverage, particularly for the southern portion of the basin, which was enabled by blending data from multiple satellite instruments $[8,14,30]$.

\subsubsection{MODIS-Aqua SST Data}

MODIS-Aqua Global Level 3 Mapped Thermal SST product relies on information derived from the 11 and $12 \mu \mathrm{m}$ thermal infrared (IR) bands (MODIS channels 31 and 32). SST data is available for both the daytime and nighttime overpasses for different averaging periods, ranging from daily to annual, gridded at $0.041^{\circ} \times 0.041^{\circ}$ resolution [37]. For this study, we utilized the monthly MODIS-Aqua Daytime SST data product for the period from July 2002 to May 2017 from the latest released version 2014.0.

\subsubsection{Advanced Very High Resolution Radiometer (AVHRR) Pathfinder SST Data}

The $4 \mathrm{~km}$ Advanced Very High Resolution Radiometer (AVHRR) Pathfinder Version 5 SST dataset is a reanalysis of historical AVHRR data that has been improved using extensive calibration, validation, and other information to yield a consistent, research quality time series for global climate studies [38,39]. The collection of National Oceanic and Atmospheric Administration (NOAA) satellite platforms that is used in the AVHRR Pathfinder SST time series includes NOAA-7, NOAA-9, NOAA-11, NOAA-14, NOAA-16, NOAA-17, and NOAA-18. In this study, we used the monthly daytime SST data for the time period from September 1997 to June 2002 to extend our analysis farther back in time than is possible with the MODIS-Aqua SST dataset alone, and to provide better temporal consistency with the OC-CCI dataset. As a check, we compare the AVHRR SST data and the MODIS Aqua SST data from July 2002 to December 2009 in order to characterize the systematic observational differences between the two datasets. We adjust these differences to produce a combined SST dataset for the Red Sea that extends from September 1997 to December 2016.

2.1.4. Modern-Era Retrospective Analysis for Research and Applications Version 2 (MERRA-2) Dust Reanalysis Data

The Modern-Era Retrospective analysis for Research and Applications version 2 (MERRA-2) is an atmospheric reanalysis dataset that is extending from January 1980 to present that is produced by the National Aeronautics and Space Administration (NASA) based on historical analysis using the Goddard Earth Observing System Model, Version 5 (GEOS-5) with its Atmospheric Data Assimilation System (ADAS), version 5.12.4. In order to assess the role of dust-related impact in the Red Sea, we use the NASA Goddard Online Interactive Visualization ANd aNalysis Infrastructure (GIOVANNI) tool [40] in order to obtain and process the monthly mean MERRA-2 data, including the field "Dust Scattering AOT $550 \mathrm{~nm}^{\prime \prime}$, which we designate as dust aerosol optical depth (DAOD) [41], as well as "Dust Dry Deposition" for "Bin-1" through "Bin-5" and "Dust Wet Deposition" "Bin-1" through "Bin-5", and "Surface Wind Speed" [42]. All the MERRA-2 data used is at $0.5^{\circ} \times 0.625^{\circ}$ resolution covering the period from September 1997 to December 2016.

\subsubsection{Multi-Angle Imaging SpectroRadiometer (MISR) Aerosol Optical Depth (AOD) Data}

The Multi-angle Imaging SpectroRadiometer (MISR) instrument has been operational on the NASA Terra satellite since early 2000 and it provides observations of the daytime portion of the Earth from nine viewing directions in four spectral bands with an instrument swath of $400 \mathrm{~km}$. In this research, we use the monthly MISR (MIL3MAE.004) AOD product at $558 \mathrm{~nm}$, which is gridded at $0.5^{\circ}$ spatial resolution [43], in order to investigate the relationship between dust aerosols and Chl- $a$ events in the Red Sea for one event, namely June 2010. Studies have shown that MISR AOD retrievals over desert sites tend to have better agreement with Aerosol Robotic Network (AERONET) ground-based measurements than MODIS, especially for low AODs, and MISR provides a useful complement to 
MODIS AODs by capturing individual aerosol events, while still reproducing the overall aerosol climatology [44,45].

\subsubsection{Cloud-Aerosol Lidar and Infrared Pathfinder Satellite Observations (CALIPSO) AOD Data}

The Cloud-Aerosol Lidar and Infrared Pathfinder Satellite Observations (CALIPSO) satellite [46] has flown in formation with the sun-synchronous, near-polar A-train constellation of Earth observing satellites since 28 April 2006. Developed as a collaboration between the French space agency, Centre National d'Etudes Spatiales (CNES), and NASA, the main scientific objective of the CALIPSO mission is to provide range-resolved information on the vertical distribution of aerosols and clouds. The Cloud Aerosol Lidar with Orthogonal Polarization (CALIOP) instrument uses a two-wavelength elastic backscatter Nd:YAG laser that transmits linear polarized light at $532 \mathrm{~nm}$ and $1064 \mathrm{~nm}$, coupled with a receiver telescope of $1 \mathrm{~m}$ diameter that measures the perpendicular and parallel components of the attenuated backscatter at $532 \mathrm{~nm}$ and the total attenuated backscatter at $1064 \mathrm{~nm}$ [47]. The CALIOP Level 2 (L2) data includes information on the aerosol and cloud backscatter coefficient at $532 \mathrm{~nm}$ and $1064 \mathrm{~nm}$, and the particle depolarization ratio at $532 \mathrm{~nm}$ [48]. Both aerosol and cloud profile datasets are provided at $5 \mathrm{~km}$ horizontal and $60 \mathrm{~m}$ vertical resolution, for an altitude range of up to $8.3 \mathrm{~km}$ above mean sea level (AMSL). The CALIPSO Version 3 (V3) algorithm discriminates aerosols into six subtypes: (i) clean marine; (ii) dust; (iii) polluted continental; (iv) clean continental; (v) polluted dust; and (vi) smoke [49]. The CALIPSO algorithm further assigns a specific Lidar Ratio (LR) to each aerosol subtype, which can used in conjunction with the retrieved backscatter coefficient profiles for the derivation of the extinction coefficient profiles at various levels within the atmosphere [50].

Dust aerosol and the optical properties of dust have been extensively studied using CALIOP data [51-56]. In the present study, the CALIOP V3 L2 Aerosol Profile product is implemented to derive pure dust extinction coefficient profiles over the Red Sea for the period of 2007 to 2015. The Climatological Dust Extinction coefficient profiles (Clim-DE) dataset, reported at $1^{\circ} \times 1^{\circ}$ spatial resolution, are also used [57]. The Clim-DE dataset is based on the CALIPSO pure dust product [54] and the ESA-LIVAS climatology (via http:/ / lidar.space.noa.gr:8080/livas/). The Clim-DE product has been used in previous studies to investigate the vertical structure of Saharan dust transport over Europe [58] and the three-dimensional features of the dust burden over East Asia [59].

\subsection{Methods}

To investigate the variation of dust deposition and its impact on oceanic production in the Red Sea region, a multi-sensor approach was used to evaluate Chl- $a$ variability associated with dust deposition using DAOD and other environmental parameters, such as wind speed and SST. Using the MODIS-Aqua Chl-a product, Li et al. [19] revealed a two-month lag correlation positive dust anomalies and high Chl- $a$ anomalies, as well as a two-month lag correlation between negative SST anomalies and high Chl- $a$ anomalies. In this work, we use the OC-CCI dataset to further test and validate the results obtained from $\mathrm{Li}$ et al. [19]. Moreover, this research explores the possible factors that are contributing to the influence of aeolian dust on summertime phytoplankton blooms in the Red Sea by investigating other dust-related factors, namely, wind speed, dust sources, and dust deposition type.

A time-averaged map of Chl- $a$ concentration for the Red Sea was generated with OC-CCI data from September 1997 to December 2016 (Figure 1). The map shows the same meridional pattern of Chl- $a$ concentration, as in previous research $[3,19]$ - high values appear near the entrance of Gulf of Aden in the south and along nearby coastal areas; the northern Red Sea $\left(20^{\circ} \mathrm{N}\right.$ to $\left.28^{\circ} \mathrm{N}\right)$ is lower in Chl- $a$ than the southern Red Sea $\left(13^{\circ} \mathrm{N}\right.$ to $\left.20^{\circ} \mathrm{N}\right)$, while the region that is south of the Farasan Islands $\left(13^{\circ} \mathrm{N}\right.$ to $\left.17^{\circ} \mathrm{N}\right)$ has higher Chl- $a$ amounts than the region just to the north $\left(17^{\circ} \mathrm{N}\right.$ to $\left.20^{\circ} \mathrm{N}\right)$. Note, however, that the range of Chl- $a$ values $\left(0.15\right.$ to $\left.2.15 \mathrm{mg} / \mathrm{m}^{3}\right)$ from the OC-CCI dataset is smaller than the range that was reported for the MODIS-Aqua dataset $\left(0.1\right.$ to $\left.5 \mathrm{mg} / \mathrm{m}^{3}\right)$ [19]. Based on the abundance and spatiotemporal distribution of surface Chl-a, in Figure 1, we partition the Red Sea into four domains at specific, integer latitudinal boundaries for convenience. The four regions, from north to south, 
are designated the Northern Red Sea (NRS) $\left(28^{\circ} \mathrm{N}\right.$ to $\left.24^{\circ} \mathrm{N}\right)$, the North Central Red Sea (NCRS) $\left(24^{\circ} \mathrm{N}\right.$ to $\left.20^{\circ} \mathrm{N}\right)$, the South Central Red Sea (SCRS) $\left(20^{\circ} \mathrm{N}\right.$ to $\left.17^{\circ} \mathrm{N}\right)$, and the Southern Red Sea (SRS) $\left(17^{\circ} \mathrm{N}\right.$ to $\left.13^{\circ} \mathrm{N}\right)$. Note that these designations are slightly different than those that were used in previous studies [3,19].

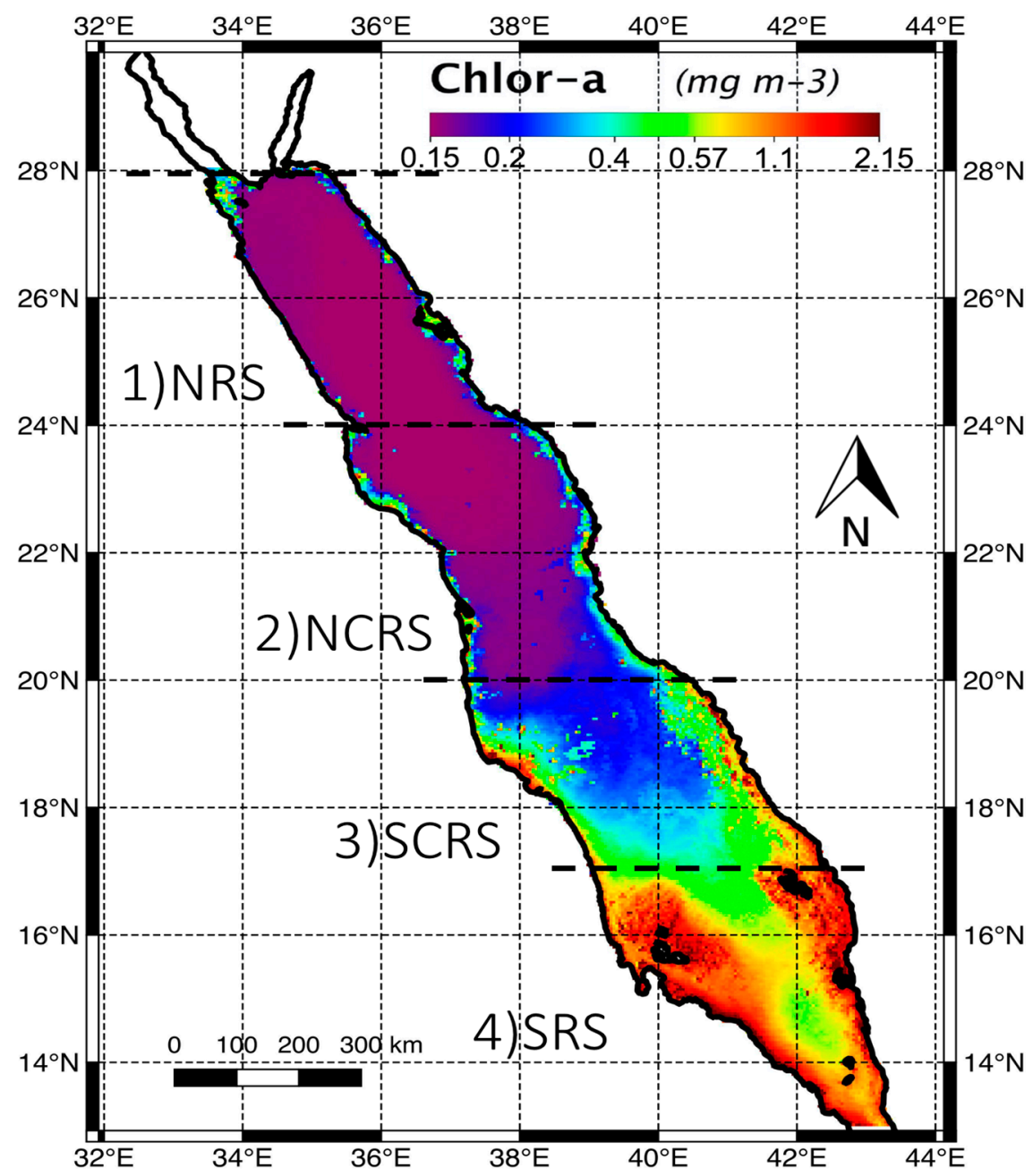

Figure 1. Ocean Color Climate Change Initiative (OC-CCI) Chl- $a\left(\mathrm{mg} \mathrm{m}^{-3}\right)$ Level 3 monthly OC-CCI Chl- $a$ data averaged for the Red Sea from September 1997 to December 2016. The four regions labeled consecutively starting from the north to south are the Northern Red Sea (NRS), North-Central Red Sea (NCRS), South-Central Red Sea (SCRS), and Southern Red Sea (SRS).

For each of the four regions, time series analyses of the nearly 20 years (September 1997 to December 2016) monthly data for Chl- $a$, DAOD, SST, and wind speed were performed using scaled values, anomalies, and lag (cross) correlation. The scaled values, $S V$, are calculated by finding the mean of the entire time series, $x_{m}$, subtracting this from each monthly value, $x_{i}$, and then normalizing the result by the mean of the time series. Formally, this is represented by the equation:

$$
S V=\frac{x_{i}-x_{m}}{x_{m}}=\frac{x_{i}}{x_{m}}-1
$$

The use of the $S V$ allows for time series of different variables to be represented on a similar scale and reveals potential long-term trends in the data, which are represented as deviations from the mean of the time series, $x_{m}$. 
Due to the large seasonality in the Red Sea, it is often helpful to consider the monthly anomalies, as given by:

$$
a_{i}=x_{i}-\bar{x}
$$

where $\bar{x}$ is the mean value that is calculated for that month from the entire dataset. To make the different datasets comparable, the monthly anomalies are scaled by $\sigma$, the standard deviation of the values for that month, which we term the Z-score:

$$
\mathrm{Z}-\text { score }=\frac{a_{i}}{\sigma}=\frac{x_{i}-\bar{x}}{\sigma}
$$

In order to uncover the relationships between two different parameters, both standard correlation and lag (cross) correlation analyses were done. The standard (Pearson) correlation coefficient, $r$, between two time series of variables, $x$ and $y$, with $N$ elements can be expressed as:

$$
r=\frac{\sum_{i=1}^{N}\left(x_{i}-\bar{x}\right)\left(y_{i}-\bar{y}\right)}{\sqrt{\sum_{i=1}^{N}\left(x_{i}-\bar{x}\right)^{2}} \sqrt{\sum_{i=1}^{N}\left(y_{i}-\bar{y}\right)^{2}}}=\frac{\operatorname{Cov}(x, y)}{\sigma_{x} \sigma_{y}}
$$

where, $\operatorname{Cov}$ is the covariance function, and $\sigma_{x}$ and $\sigma_{y}$ represent the standard deviation of the $x$ and $y$ time series, respectively. The correlation coefficient can assume values between -1 and +1 , with -1 representing perfect anti-correlation and +1 representing perfect correlation. Finally, as in Li et al. [19], we consider the lagged (cross) correlation $r(k)$, for lag $k$, which is given by:

$$
r(k)=\frac{\sum_{i=1}^{N-k}\left(x_{i}-\bar{x}\right)\left(y_{i+k}-\bar{y}\right)}{\sqrt{\sum_{i=1}^{N}\left(x_{i}-\bar{x}\right)^{2}} \sqrt{\sum_{i=1}^{N}\left(y_{i}-\bar{y}\right)^{2}}}=\frac{\operatorname{ccvf}(x, y)}{\sigma_{x} \sigma_{y}}
$$

where, ccvf is the cross-covariance function.

When creating cross-correlations maps, all of the data are re-gridded to the same resolution using a bi-linear re-gridding algorithm. These maps reflect the relationships between phytoplankton-represented by $\mathrm{Chl}-a$-and other atmospheric and oceanic factors in different regions within Red Sea. Lagged correlation maps, in particular, are used to attempt to uncover the mechanisms that are underlying the residence times of dust in the Red Sea and the release of bioavailable Fe into the oceanic mixed layer and its resulting effects on ocean productivity $[60,61]$.

\section{Results}

\subsection{Time Series of Scaled Values for Chl-a, DAOD, and SST}

The time series of the SV for three of the datasets, Chl-a from OC-CCI (green), DAOD from MERRA-2 (blue), and SST from blended AVHRR and MODIS-Aqua data (red) are shown in Figure 2 for the different regions of the Red Sea depicted in Figure 1.

A strong seasonal variation in all of the variables is immediately apparent, but is clearest in the SST data. In all four regions, the SST is lowest near the beginning of the calendar year (January-February), and highest in near the end of boreal summer and the beginning of boreal autumn (August-October). Close inspection reveals small, but systematic differences from one region to the next. The SST cools off slightly earlier in the SRS and warms slightly later, especially relative to the NRS. The magnitude of the SST SV is largest in the NRS and smallest SCRS, meaning that larger deviations from the mean are seen in the NRS.

There is also strong seasonality to dust events, particularly in the SRS, as shown in the time series of $S V$ for DAOD. Visually, there is also good correspondence between the $S V$ for DAOD and SST in the SRS, with elevated levels of DAOD corresponding to periods of elevated SST and decreased levels of DAOD corresponding to periods of lower SST. This relationship becomes progressively weaker to the north, with the NRS sometimes showing elevated DAOD events when the SST is near the mean value 
( $S V$ near zero). The peak in the DAOD in the NRS tends to occur in the late boreal spring (April-May), with negative $S V$ in the autumn. These results indicate that different mechanisms are responsible for dust generation in the northern parts of the Red Sea as compared to the southern regions.
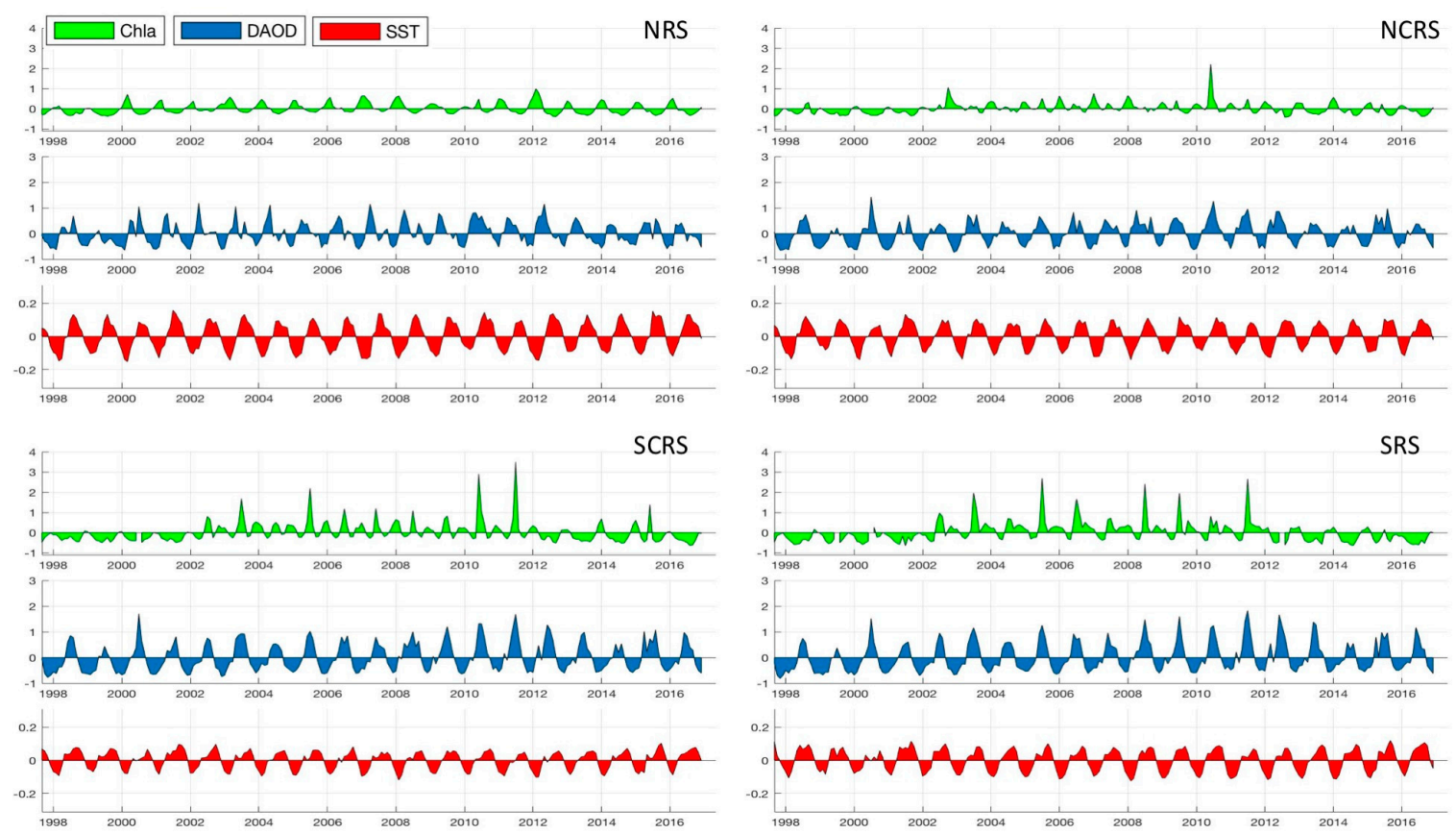

Figure 2. Time series of scaled values (see Equation (1)) for Chl- $a$, dust aerosol optical depth (DAOD) (MERRA-2 Dust Scattering AOT in $550 \mathrm{~nm}$ ), and sea surface temperature (SST) for the four regions of the Red Sea represented in Figure 1.

The $S V$ of Chl- $a$ shows strong seasonality in the NRS, where Chl- $a$ anomalies appear to be nearly perfectly anticorrelated with SST anomalies, meaning that low SSTs correspond to high Chl- $a$, and vice versa. The other portions of the Red Sea fail to show such a strong relationship. In the NCRS, positive $S V$ values of Chl- $a$ can correspond to positive $(2002)$, negative $(2007,2007)$, and near zero $(2010) S V$ values for SST. Visually, there appears to be little relationship with DAOD in the NRS. In the SCRS, the $S V$ for Chl- $a$ seems to follow a six-month cycle, with a peak in January and another around June. This relationship is also apparent in the SRS. Positive $S V$ values for Chl- $a$ correspond well to positive $S V$ values for DAOD, but with $S V$ values that are near zero for SST. Finally, in the SRS, positive $S V$ values in Chl- $a$ lead the maxima in $S V$ values for SST slightly, and again correspond nearly perfectly with positive $S V$ values for DAOD.

When considering the largest positive excursions in $S V$ for $C h l-a$, we note that these occur mainly in the southern part of the Red Sea, with the summers of 2011, 2010, 2005, and 2003 having strong events that are larger in magnitude than the typical wintertime Chl- $a$ enhancements. Note that the Chl- $a$ event that was identified in the MODIS-Aqua dataset in summer 2015, and was discussed in detail in Li et al. [19], does not rank as one of the largest Chl- $a$ events in the OC-CCI dataset, but is visible as one of the few outliers in the later part of the time series for the SCRS. The large positive Chl- $a$ events in 2011, 2005, and 2003 are significant in both the SCRS and the SRS, but have small or even negative $S V$ in the NCRS and NRS. The 2010 summertime event in the SCRS is weak in the SRS, but is the largest event in the NCRS. The second largest event in the NCRS is in October 2002, and it appears to be confined primarily to this region. 


\subsection{Time Series of Z-Scores for Chl-a, DAOD, and SST}

The large seasonality evident in all four regions of the Red Sea in SST, DAOD, and Chl- $a$ in Figure 2 tends to obscure significant monthly anomalies in these parameters. For this reason, we show the Z-scores over the different regions of the Red Sea in Figure 3. Recall that the Z-scores represent the monthly values, with the long-term monthly mean subtracted, and divided by the standard deviation of the monthly values (see Equation (3)). A Z-score that is equal to one represents a monthly value that differs from the long-term mean by one standard deviation. If the data are normally distributed, then the expectation is that $95 \%$ of the data will have a Z-score $\leq 2$, and only $0.3 \%$ of the data will have a Z-score $>3$. Of the three parameters, the only one that appears to be nearly normally distributed is the SST. Chl- $a$ and DAOD Z-scores are skewed positive in all four regions, meaning that positive anomalies are more likely than negative anomalies.
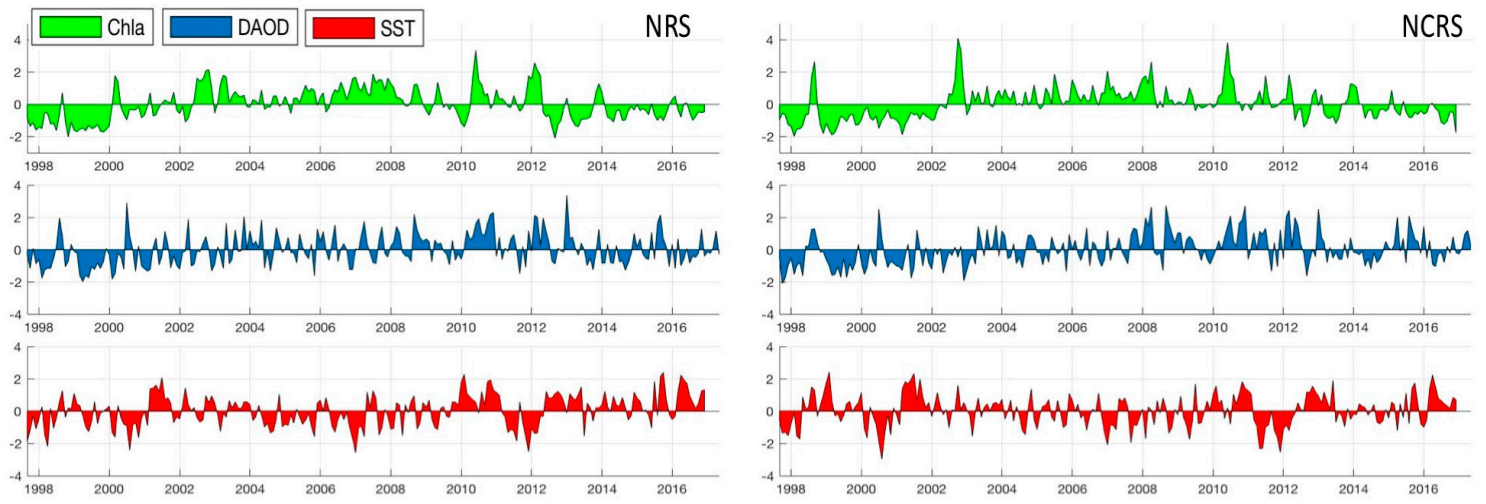

SCRS
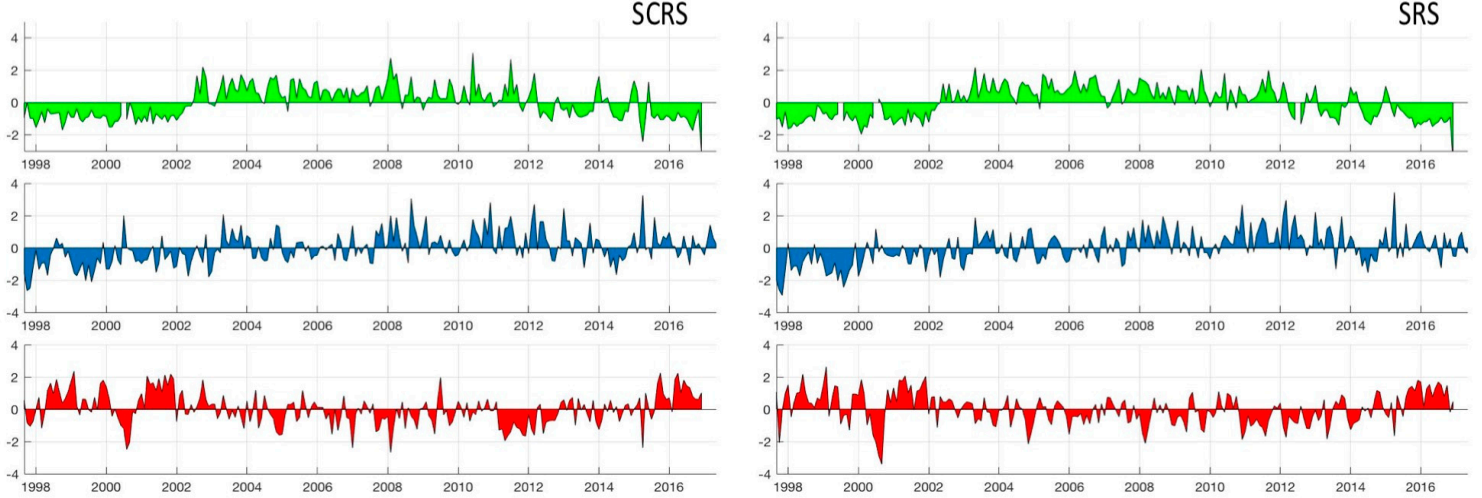

Figure 3. Time series of Z-scores (see Equation (3)) for Chl- $a$, DAOD (MERRA-2 Dust Scattering AOT in $550 \mathrm{~nm}$ ), and SST for the four regions of the Red Sea represented in Figure 1.

The SST anomalies tend to be positive prior to 2002 in both the SCRS and SRS, with a notable negative anomaly in the later part of 2000. Other negative anomalies are apparent in 2011 and 2012 in all of the regions, with the intervening years showing small anomalies of both signs. The end of the SST record in 2015/2016 shows positive anomalies that may be related to the powerful El Niño in 2016, that made it the warmest year on record, with the World Meteorological Organization Provisional Statement on the State of the Climate noting that 2013-2017 could be the warmest five-year period on record [62].

The DAOD anomalies appear to be primarily negative prior to mid-2000. This happens to be when MODIS-Terra data became available, so the inclusion of this dataset into the MERRA-2 DAOD reanalysis time series likely introduces temporal inhomogeneity. With the exception of a few positive outliers, and the time period between 2010 and 2012, there is no clear pattern to the DAOD anomalies, especially late in the time series. The large positive DAOD anomaly in 2000 occurs in all four regions 
and it is correlated with a strong negative SST anomaly. However, when comparing across the regions, the largest DAOD anomaly corresponds to the smallest SST anomaly, and vice versa. Other DAOD anomalies appear in late 2010 and 2013 in all four regions, but there does not seem to be any relationship with SST. Finally, the large DAOD anomaly in 2015 only occurs in the SRS and SCRS, where it correlates well with a negative SST anomaly, but there is no DAOD anomaly at all in the NCRS or the NRS.

Even more than the DAOD dataset, the Chl- $a$ Z-score time series shows clear temporal inhomogeneity. Visually, it is possible to separate the Chl- $a$ time series into three distinct periods that are common to all four regions. The first period is prior to mid-2002, where the negative anomalies dominate in all the regions, with the exception of a single peak event in the NCRS and NRS in late 1998. Also notable in this time period are the gaps in the time series in the SCRS and SRS. Table 1 lists the time period of each of the four sensors used to construct the OC-CCI Chl- $a$ dataset [31].

Table 1. Information of the Sensors Used in the OC-CCI Dataset.

\begin{tabular}{cccc}
\hline Sensor Number & Sensor Name & Start Time & End Time \\
\hline 1 & SeaWiFS & September 1997 & December 2010 \\
2 & MODIS (Aqua) & July 2002 & On-going \\
3 & MERIS & April 2002 & April 2012 \\
4 & VIIRS & January 2012 & On-going \\
\hline
\end{tabular}

According to Table 1, prior to mid-2002 only the SeaWiFS sensor was used to generate the OC-CCI Chl- $a$ time series, meaning that persistent clouds or dust could obscure the underlying water surface, thus resulting in a data gap. The introduction of additional sensors helped to mitigate this issue $[8,14,30]$. The second time period runs from mid-2002 to early 2012 and is characterized by primarily positive Chl- $a$ anomalies. Only the NRS shows any significant negative anomaly during this period, which occurs in early 2010. Table 1 shows that MERIS was no longer included in the OC-CCI Chl- $a$ dataset after April 2012, due to the loss of contact with the Envisat-1 platform. Around the same time, the VIIRS data began to be included. The loss of MERIS and the inclusion of VIIRS corresponds to the third period evident in the time series, which is characterized by primarily negative Chl- $a$ anomalies. Notable exceptions are a strong positive anomaly at the beginning of 2014 that can be seen in all four Red Sea regions, and another large anomaly at the beginning of 2015, which seems to be confined to the SCRS and SRS. The June 2015 event that is discussed in detail in Li et al. [19] is apparent in the Z-score time series, but only in the SCRS.

The time series shown in Figure 3 are suggestive of relationships among these three variables, particularly in the SCRS, and, to a lesser extent, the SRS, as discussed in our earlier work [19]. However, the temporal in homogeneities that are apparent in the both the Chl- $a$ time and DAOD series indicate that caution must be exercised before drawing too strong conclusions from these particular datasets. We explore the representativeness of the datasets for different time periods in our later discussion (Section 3.3).

\subsection{Comparision of Sensors Used in OC-CCI Data}

When comparing the monthly means of Chl- $a$ between MODIS and OC-CCI, (analysis done but not shown here), a low bias in OC-CCI relative to MODIS-Aqua at large Chl- $a$ values was observed with high outliers in the mean for low Chl- $a$ values. Looking at the monthly median values, the low bias remained, but the high bias is more or less eliminated. We believe that MERIS is the cause of this bias and for that we decided to run a comparative analysis between Chl- $a$, obtained from the OC-CCI data, against SST, DAOD, and wind observations and anomalies during three different periods amongst the sensors that aee listed in Table 1 . These three periods represents data before MERIS (1998-2002), during MERIS (2003-2011) and after MERIS (2012-2016). Figure 4a-c, show correlation maps (lag $=0$ ) of SST, DAOD and WINDSPEED with Chl- $a$ for each of the stated periods against the whole entire period (1998-2016). Similar behavior across the different time periods should be normal 
and is expected, however, cases with discrepancies and inconsistent behavior will be discussed and highlighted in the following.
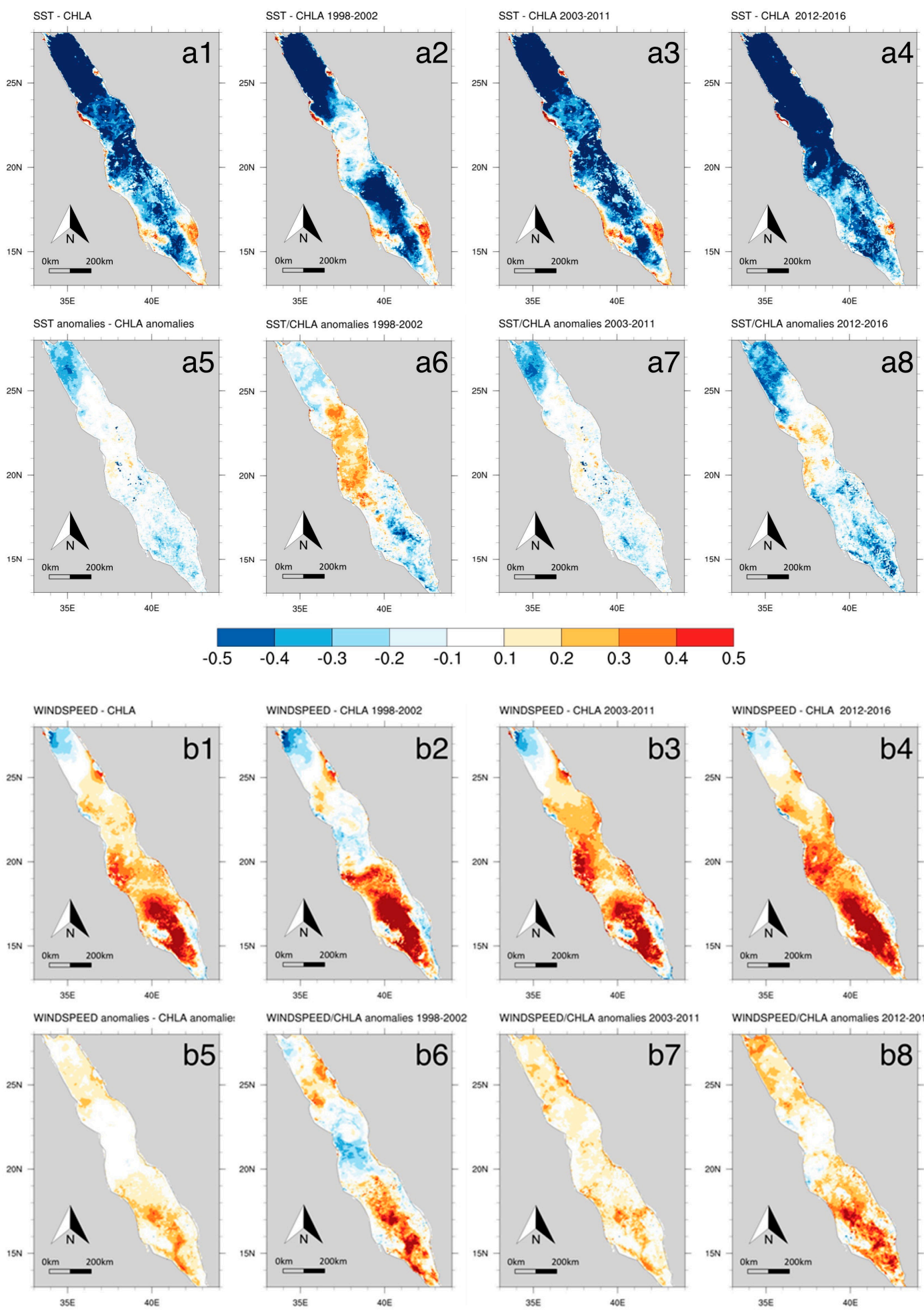

WINDSPEED/CHLA anomalies 1998-2002

WINDSPEED/CHLA anomalies 2012-2016
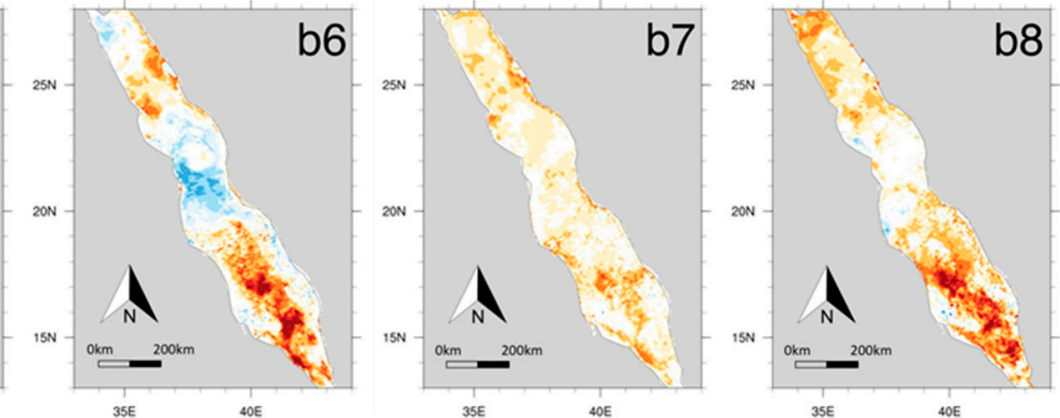

$\begin{array}{cccccccccc}-0.5 & -0.4 & -0.3 & -0.2 & -0.1 & 0.1 & 0.2 & 0.3 & 0.4 & 0.5\end{array}$

Figure 4. Cont. 

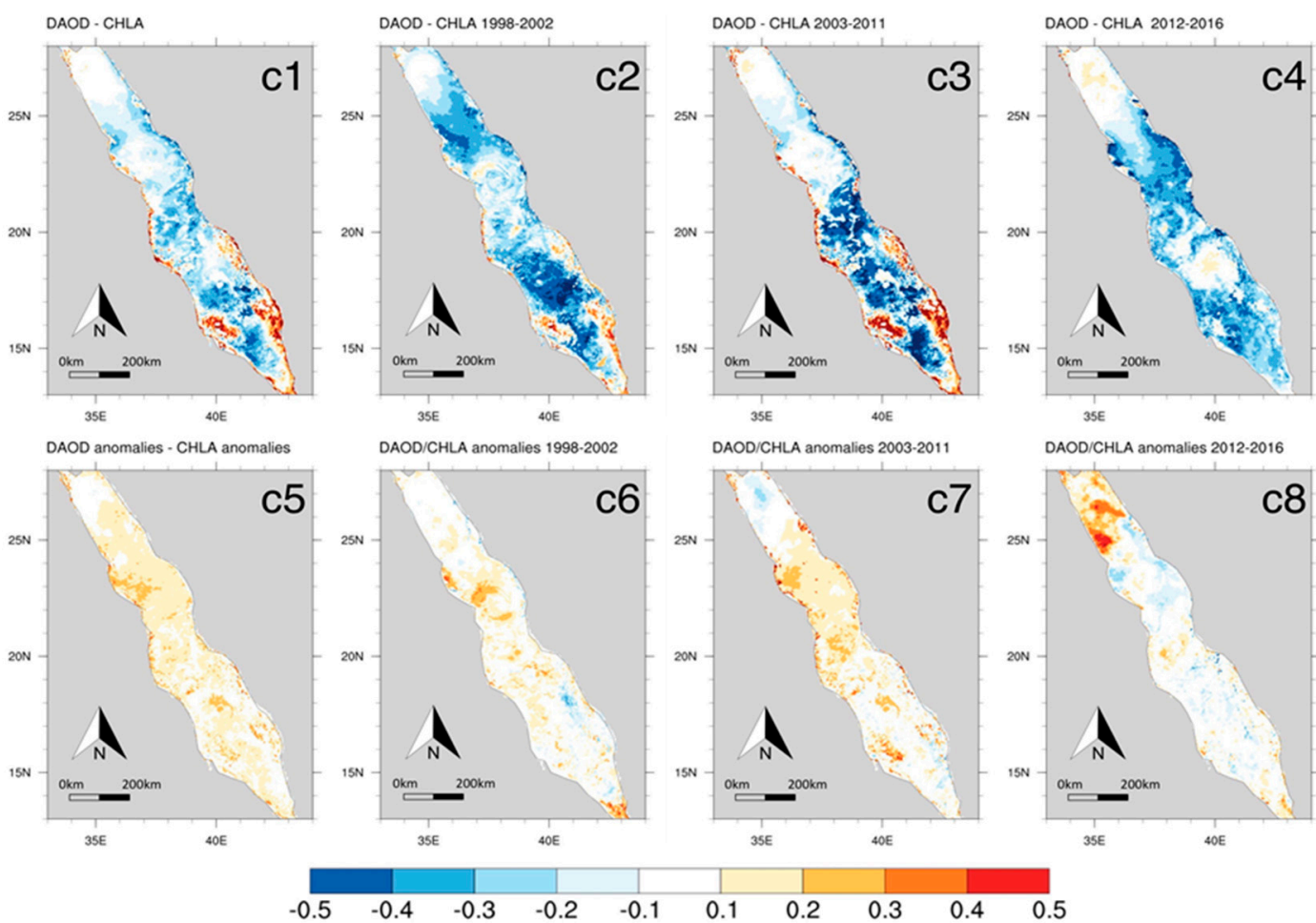

Figure 4. Cross Correlation analysis at lag 0 for actual values and anomalies of SST (a1-a8), WINDSPEED (b1-b8) and DAOD (c1-c8) (MERRA-2 Dust Scattering Aerosol Optical Depth (AOT) in $550 \mathrm{~nm}$ ) with Chl- $a$, for entire period (1998-2016) (first column), before MERIS (1998-2002) (second column), during MERIS (2003-2011) (third column), and after MERIS (2003-2011) (fourth column).

Over the entire time period 1998-2016, SST and Chl- $a$ observations exhibit a consistent negative correlation during the three different periods (Figure 4(a1)), whereas the anomalies (Figure 4(a5)) of both the northern and southern-most regions of the Red Sea stood out. This could be owed to the upwelling of cooler and nutrient-rich seawater [17] and the induction of a cool and nutrient-rich current from Gulf of Aden [3,11,14], respectively. However, during the period 1998-2002, the central Red Sea region $\left(19^{\circ} \mathrm{N}-23^{\circ} \mathrm{N}\right)$ exhibited a low correlation that is presented by the white colored area (Figure 4(a2)) while the SST and the Chl- $a$ anomalies experienced a positive correlation (Figure 4(a6) due to the influence of eddy activity [2,19], a behavior that is also observed during the period 2012-2016 (Figure 4(a8)).

A consistent correlative behavior between wind speed and Chl- $a$ observations is clear during all of the time periods, where the northern Red Sea exhibits a negative correlation, while the middle and southern Red Sea exhibits a positive correlation (Figure 4(b1-b4)). This could be attributed to the fact that summer seasons experience the strongest periods of wind speed that can drive the Gulf of Aden currents into the Red Sea, leading to the phytoplankton bloom of the central and southern regions [14]. While the northernmost region shows phytoplankton blooming, mainly during the winter period due to weaker wind. For wind speed and Chl- $a$ anomalies, the entire region exhibits a positive correlation (Figure 4(b5-b8)). An exception is observed during 1998-2002 (Figure 4(b6)), where the northern and central Red Sea $\left(19^{\circ} \mathrm{N}-23^{\circ} \mathrm{N}\right)$ exhibited a different correlative behavior from the other periods. This can be attributed to the influence of wind stirring up the seawater to enhance nutrient mixing and the eddy activities over the two regions, respectively.

As for the DAOD and Chl- $a$, it is rather complicated because of the lack of observations during major dust events, which make it hard to conclude a definitive correlative behavior. However, we observed an overall negative correlation between DAOD and Chl- $a$ observations (Figure 4(c1-c4)) during all of the time periods, but with rather exceptional positive correlations in the coastal and 
southern regions of the Red Sea. This positive correlative behavior is not clear during the period 2012-2016 (Figure 4(c4)), mainly because the Chl- $a$ summer observations are insufficient due to major dust events. It is also noteworthy that during 1998-2002, the negative correlation in $23^{\circ} \mathrm{N}-25^{\circ} \mathrm{N}$ was stronger than that of 2003-2011, something that we need to look into to better understand it. For DAOD and Chl- $a$ anomalies (Figure 4(c5-c8)), a positive correlative behavior is observed over the whole region with a very strong positive correlation in the NRS during 2012-2016 (Figure 4(c8)), which may be attributed to eddy's or wind stirring up influence (Figure 4(b8)) or wet deposition.

In conclusion, we believe that the three different outlined periods more or less behaved similarly when compared to the entire period's behavior, namely during 1998-2016. However, we still acknowledge the presence of few differences that were discussed above. This finding strongly supports the validity of using OC-CCI Chl- $a$ data to study its cross correlative behavior with SST, wind speed, and DAOD.

\subsection{Anomaly Comparison of Chl-a Concentration and Other Factors for June 2010}

Figure 5 shows the monthly anomaly, $a_{i}$ (see Equation (2)), maps in the Red Sea for June 2010 for Chl- $a$, SST, and AOD, as well the related meteorological parameters dust dry and wet deposition, and wind speed. The latter three parameters are taken from the MERRA-2 reanalysis. June 2010 was selected because it has a large positive Chl- $a$ anomaly, which is particularly apparent in the NCRS and SCRS time series (see Figure 3).
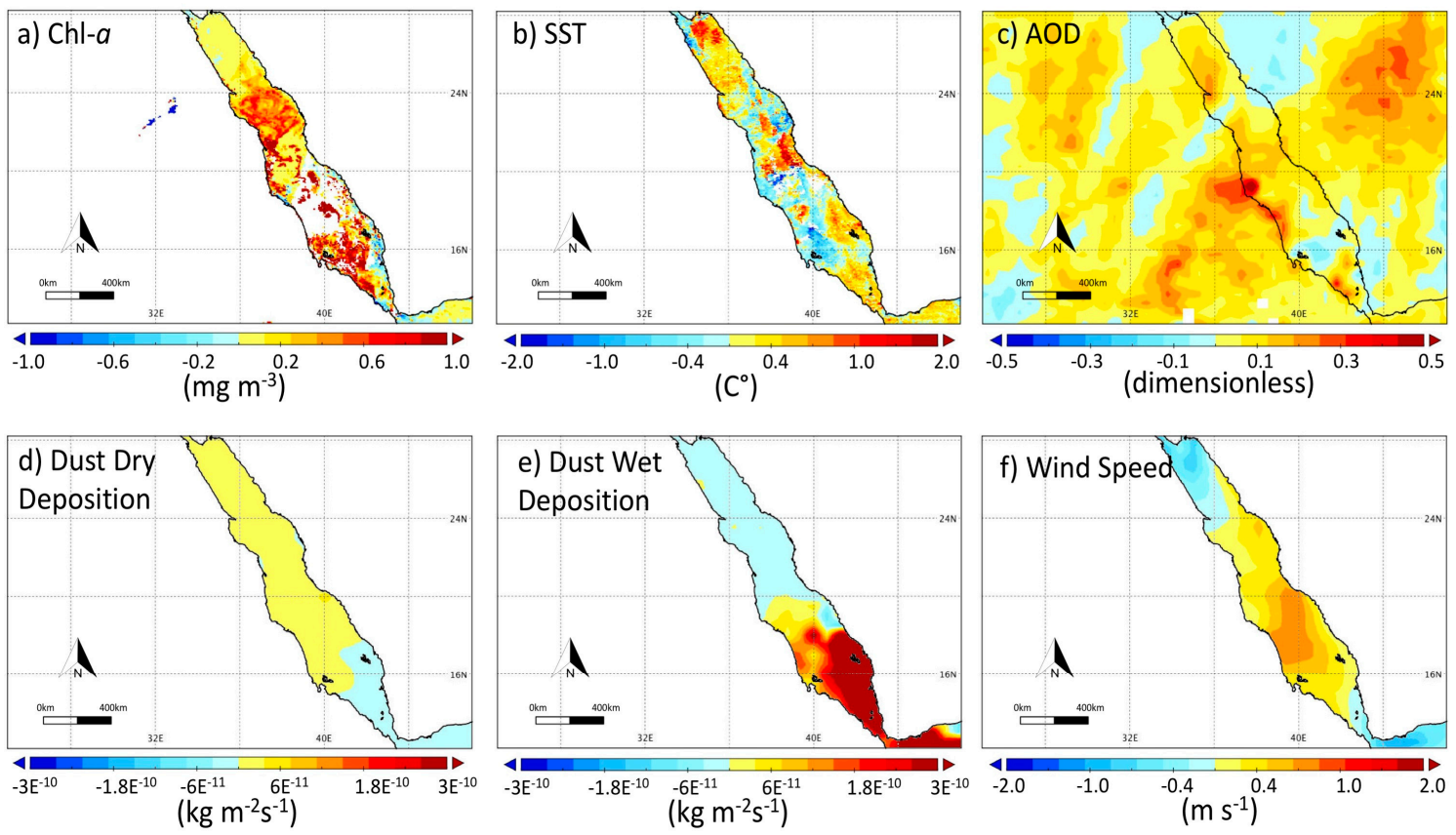

Figure 5. Monthly anomaly maps of (a) Chl- $a$; (b) SST; (c) AOD (MISR); (d) Dust dry deposition; (e) Dust wet deposition; and (f) Wind Speed for June 2010.

The map of the Chl- $a$ anomaly field in Figure 5a shows a large area of high Chl- $a$ at around $16^{\circ} \mathrm{N}$ in the SCRS, with a somewhat smaller positive anomaly around $22^{\circ} \mathrm{N}$ in the NCRS. Note the large region of missing data between about $17^{\circ}$ and $18^{\circ} \mathrm{N}$, which could be due to persistent clouds or dust. The SST anomalies in Figure 5b show the expected correlation in the SCRS with low SSTs in the area of elevated Chl- $a$ amounts. In the NCRS, however, the SST anomalies are slightly positive. The AOD anomaly map in Figure 5c shows slightly elevated AODs at around 0.1 over most of the Red Sea during June 2010. Higher AOD anomalies are seen around $19^{\circ} \mathrm{N}$, centered near Port Sudan, Sudan. Interestingly, negative AOD anomalies are more directly associated with the positive Chl- $a$ anomaly in the SCRS. The dust dry deposition map in Figure $5 \mathrm{~d}$ shows small positive anomalies over most of 
the region, with the exception of the extreme southern Red Sea. The dust wet deposition in Figure 5e, in contrast, has a large positive anomaly in both the SCRS and SRS, with larger positive anomalies along the eastern coastline. Comparison with Figure 5a shows that the positive Chl- $a$ anomalies are not well correlated with the increased wet deposition in these regions, however. Finally, the wind speed anomalies in Figure $5 \mathrm{f}$ show the distinct signature of the wind jet that is associated with the Tokar Gap, which is discussed in terms of its relation to the Chl- $a$ anomaly in June 2015 in Li et al. [19]. In this case, the axis of elevated wind speeds corresponds well with the missing data in the Chl- $a$ map in Figure 5 a.

\subsection{Correlation Analysis of Chl-a Anomalies with SST and DAOD Anomalies}

To further investigate the relationships between SST and the MERRA-2 DAOD with Chl- $a$, the correlation coefficients, $r$ (see Equation (4)), for the anomalies in these parameters for each month and each region within the Red Sea are given in Table 2.

Table 2. SST/Chl- $a$ and DAOD/Chl- $a$ monthly anomaly correlation coefficients for the four Regions of Red Sea. Light blue indicates negative correlation between -0.5 and -0.7 , dark blue indicates negative correlation $<-0.7$. Light red indicates positive correlation between +0.5 and +0.7 . Dark red indicates positive correlation $>+0.7$.

\begin{tabular}{cccccc}
\hline \multirow{2}{*}{ January } & & NRS & NCRS & SCRS & SRS \\
& SST/Chl- $a$ & -0.562 & -0.268 & -0.496 & -0.703 \\
& DAOD/Chl- $a$ & +0.244 & +0.407 & +0.310 & +0.314 \\
\hline \multirow{2}{*}{ February } & SST/Chl- $a$ & -0.639 & -0.355 & -0.785 & -0.592 \\
& DAOD/Chl- $a$ & +0.473 & +0.669 & +0.670 & +0.678 \\
\hline \multirow{2}{*}{ March } & SST/Chl- $a$ & -0.617 & -0.341 & -0.618 & -0.592 \\
& DAOD/Chl $a$ & +0.138 & +0.736 & +0.479 & +0.294 \\
\hline \multirow{2}{*}{ April } & SST/Chl- $a$ & -0.301 & +0.042 & +0.266 & -0.138 \\
& DAOD/Chl- $a$ & +0.243 & +0.588 & -0.160 & -0.027 \\
\hline \multirow{2}{*}{ May } & SST/Chl- $a$ & -0.151 & -0.410 & -0.419 & -0.497 \\
& DAOD/Chl- $a$ & 0.597 & +0.436 & +0.370 & +0.360 \\
\hline \multirow{2}{*}{ June } & SST/Chl- $a$ & +0.122 & -0.091 & -0.223 & -0.296 \\
& DAOD/Chl- $a$ & +0.531 & +0.521 & +0.528 & +0.122 \\
\hline \multirow{2}{*}{ July } & SST/Chl- $a$ & +0.102 & -0.263 & -0.484 & -0.672 \\
& DAOD/Chl $a$ & +0.020 & +0.250 & +0.651 & +0.674 \\
\hline \multirow{2}{*}{ August } & SST/Chl- $a$ & -0.083 & +0.391 & +0.015 & -0.099 \\
& DAOD/Chl- $a$ & +0.147 & +0.294 & +0.219 & +0.442 \\
\hline \multirow{2}{*}{ September } & SST/Chl- $a$ & -0.182 & -0.096 & -0.464 & -0.339 \\
& DAOD/Chl- $a$ & +0.509 & +0.562 & +0.526 & +0.431 \\
\hline \multirow{2}{*}{ October } & SST/Chl- $a$ & -0.107 & +0.292 & -0.228 & -0.339 \\
& DAOD/Chl- $a$ & +0.647 & +0.103 & -0.017 & +0.260 \\
\hline \multirow{2}{*}{ November } & SST/Chl- $a$ & -0.256 & +0.034 & -0.392 & -0.705 \\
& DAOD/Chl $a$ & -0.030 & +0.169 & +0.578 & +0.500 \\
\hline \multirow{2}{*}{ December } & SST/Chl- $a$ & -0.319 & -0.151 & -0.542 & -0.569 \\
& DAOD/Chl- $a$ & +0.095 & +0.083 & +0.269 & +0.212 \\
\hline
\end{tabular}

Significant negative correlations $(<-0.5)$ are colored blue and significant positive correlations $(>+0.5)$ are shaded red. Absolute values that are greater than or equal to 0.5 are shaded in light colors, and absolute values greater than 0.7 are shaded in darker colors. These limits are chosen because the coefficient of determination, $r^{2}$, is 0.25 for $r=0.5$ and approximately 0.5 for $r=0.7$. This means that $25 \%$ and $50 \%$ of the association is explained by a linear relationship between the terms for these two thresholds, respectively. This same information is plotted in Figure 6 as a monthly time series for the SST/Chl- $a$ anomaly relationship (Figure 6a) and the DAOD/Chl- $a$ anomaly relationship (Figure $6 \mathrm{~b}$ ).

As seen in Table 2, and Figure 6, SST anomalies are typically negatively correlated with Chl- $a$ anomalies, while DAOD anomalies are positively correlated with Chl- $a$ anomalies. These relationships are not unexpected, as phytoplankton tends to thrive in relatively cooler environments, while dust deposition can provide necessary nutrients, including $\mathrm{Fe}$, which helps to foster phytoplankton growth, particularly in oligotrophic waters, like the Red Sea. The correlation with the largest magnitude is -0.785 , found between SST anomalies and Chl- $a$ anomalies in February in the SCRS. This is followed 
closely by the large positive correlation of +0.736 between DAOD anomalies and Chl- $a$ anomalies in March in the NCRS. Other significant negative correlations are found in the SRS between SST anomalies and Chl- $a$ anomalies in January and November.
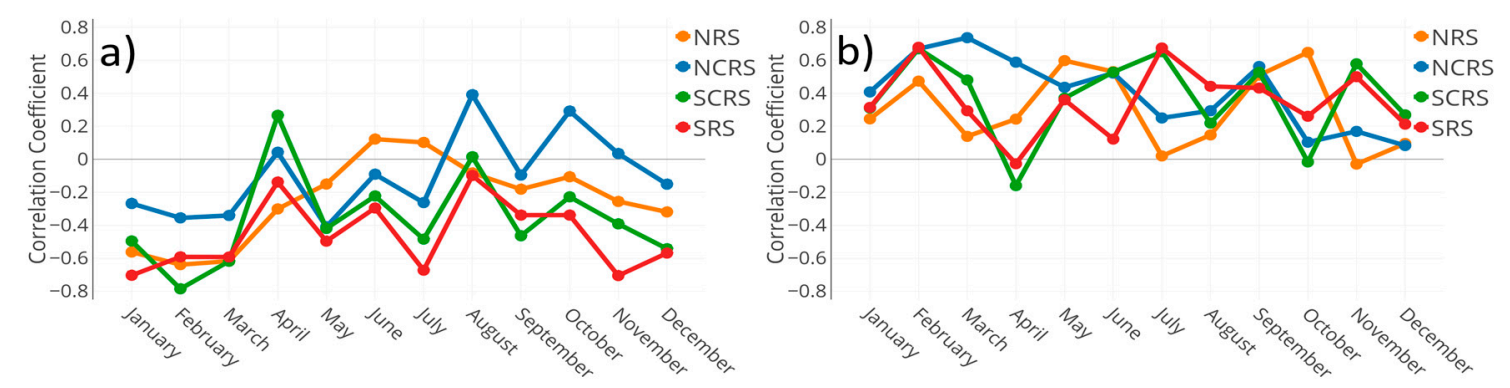

Figure 6. Time series plot of monthly anomaly correlation coefficients for the four regions of the Red Sea; (a) SST/Chl- $a$; (b) DAOD (MERRA-2 Dust Scattering AOT in $550 \mathrm{~nm}$ )/Chl- $a$.

When considering the overall temporal structure of the correlations between SST and Chl- $a$ anomalies that are shown in Figure 6a, the relationships are similar for the NCRS, SCRS, and SRS, while the NRS behaves differently. The June and July correlations in the NRS achieve their highest (positive) values, and have their largest (negative) correlations in February and March. The other regions also have large (negative) values in February and March, with much smaller absolute correlations in April, then increasingly negative correlations in May, June, and July. This behavior may reflect the boreal summer intrusion of cooler waters from the Indian Ocean through the Gulf of Aden in the south, but the magnitude of the monthly correlation is rather small between SST and Chl- $a$ in all four regions in the summertime.

The correlation between DAOD anomalies and Chl- $a$ anomalies in Figure $6 \mathrm{~b}$ shows a different pattern than Figure 6a. First, the NRS has large positive correlations in February, May, and October. The SCRS and SRS are nearly identical, with the exception of June, which may be due to the residual issues in the SRS due to clouds or persistent dust in this month. The correlation in these two regions peaks in February, falls rapidly in April, peaks again in July, then falls in October, but peaks again in November. The NCRS shows characteristics of both the NRS and the two southern regions with a broad peak in correlation centered on March, declining until July-August, with a second peak in the correlation in September.

February and March are the months that are showing the largest number of significant correlations in all regions, while August is the only month that shows no significant correlations. Significant positive anomaly correlations between DAOD and Chl-a outnumbered the significant negative anomaly correlations between SST and Chl- $a$. With the exception of February and March, the former tend to be concentrated in the boreal summer months, while the latter are more frequent in the boreal winter. Finally, the number of months with significant anomalies of either sign is largest is the SRS (9), followed by the SCRS (8), the NRS (7), and the NCRS (5). Note, however, that these results are at least partly due to the selection of the threshold for significance.

\subsection{Lag (Cross) Correlation Maps of SST, Wind Speed, and DAOD with Chl-a}

In Li et al. [19], we discovered a clear two-month lag correlation between Chl- $a$ and DAOD anomalies using a MODIS data. To expand this major finding through the longer time and to gain further understanding of how the factors discussed here influence Chl- $a$, the MERRA-2 data of DAOD and Surface Wind Speed as well as MODIS Aqua SST data are re-gridded to $4 \mathrm{~km}$ spatial resolution with linear re-gridding algorithm. This re-gridding algorithm is already applied and presented in Figure $4 \mathrm{a}-\mathrm{c}$. Through the current lag analysis, SST \& Chl- $a$ observations, and anomalies exhibits a gradually changing behavior (Figure 7(a1-a8)). For instance, we found that the negative correlation between Chl- $a$ and SST of the northern region gradually flips to a positive correlation at lag 3 due 
to a seasonal change (Figure 7(a1-a4)). Moreover, the lag 3 map (Figure 7(a4)) shows a south-north positive trend implying on the inflow of the nutritious waters from the Gulf of Aden to the Red Sea environment. Slowly dissipating/increasing behavior in the anomalies of Chl- $a$ and SST is observed as we move from 0 to 3 months lag (Figure 7(a5-a8)). It is worth noting that the SST/Chl- $a$ anomalies (Figure 7(a5-a8)) use MODIS Aqua SST data during the period of 2003 to 2016, whereas the SST/Chl- $a$ anomalies' plot during the period of 1998 to 2002 uses the AVHRR SST data (Figure 4(a6)).
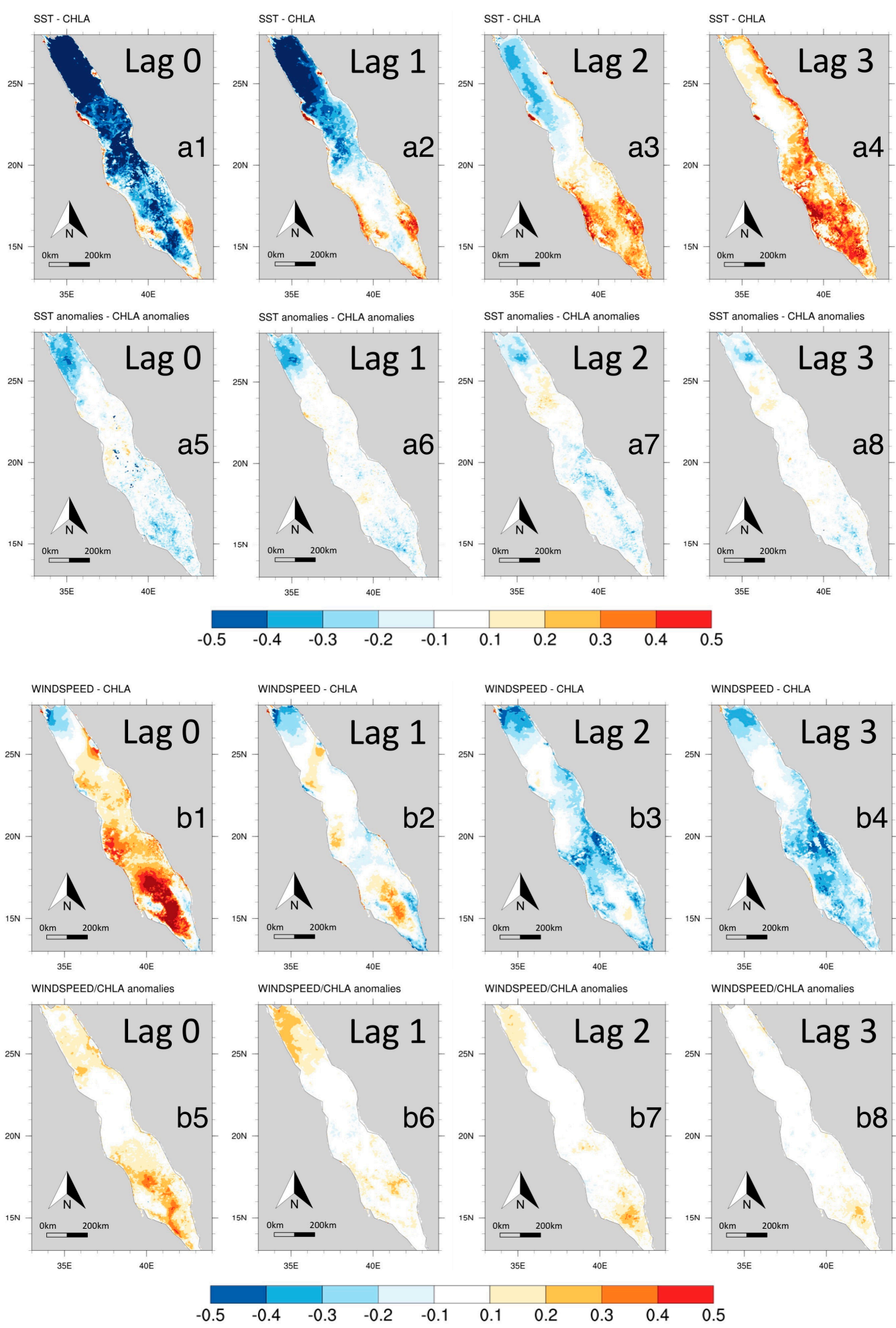

Figure 7. Cont. 


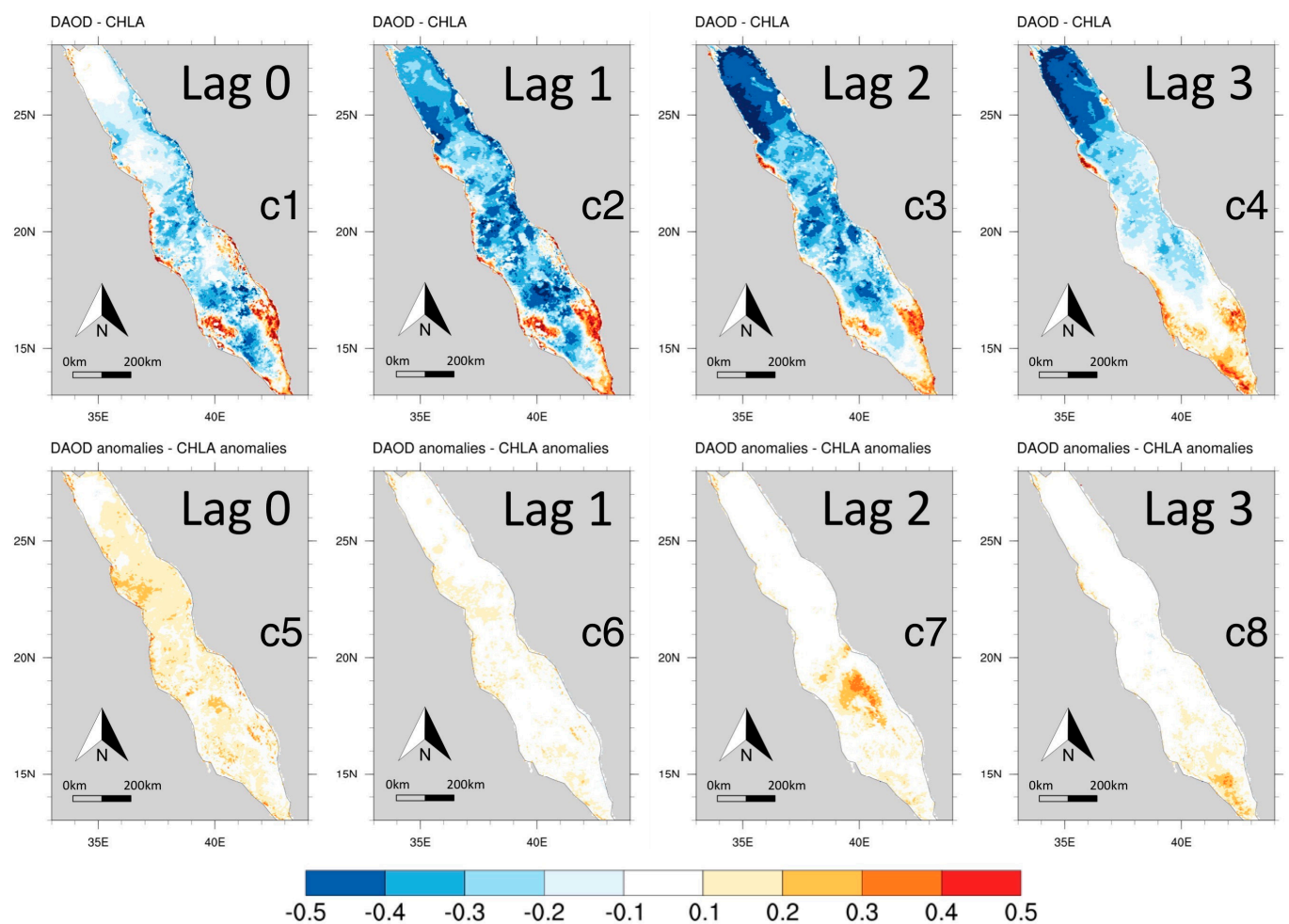

Figure 7. Cross Correlation maps of actual observations and anomalies for SST (a1-a8), WINDSPEED (b1-b8) and DAOD (c1-c8) (MERRA-2 Dust Scattering AOT in $550 \mathrm{~nm}$ ), with Chl- $a$ for a time lag of 0 month (first column), lag of one month (second column), lag of two months (third column), and lag of three months (fourth column).

The northern region of the Red Sea shows an increasing negative behavior from lag 0 to 3 months lag between the Chl- $a$ and wind speed observations (Figure 7(b1-b4)). This finding shed the light of the decline of the wind driven vertical mixing with seasonal change. On the other hand, a declining positive correlative behavior from 0 to 3 months lag is clearly observed over the northern and southern Red Sea regions between the wind speed \& Chl- $a$ anomalies (Figure 7(b5-b8)).

It is quite evident that the Red Sea environment exhibits a consistent negative correlative behavior between the Chl- $a$ and the DAOD observations (Figure 7(c1-c4)) with clear positive correlative exceptions dominating the southern region and the coastal areas. This can be cautiously attributed to possible deposition scenarios. However, it is noteworthy that the Chl- $a$ and DAOD anomalies shows a positive correlation at zero lag (Figure 7(c5)) and moving north-south trend from lag 1 to lag 3 (Figure 7(c6-c8)). The exceptional positively correlated round-shaped area at SCRS at lag-2 (Figure 7(c7)) agrees with the findings of Li et al. [19] that showed the bloom at the same region during June 2015 because of the eddy's contribution as well as the Tokar gap dust event. This indicates that the bloom of June 2015 was so profound to dominate the correlation plot, showing that the two-month lag high correlation may have resulted from this event. However, all of the plots are all about the statistical relationship, not necessarily proving the causation between the observations.

\subsection{Calipso-Based 3D Climatology of Desert Dust Aerosol over the Red Sea}

In addition to the horizontal variability of AVHRR and MODIS Aqua SST, MERRA-2 Dust Reanalysis Data, MISR AOD, and OC-CCI Chl- $a$ product, the CALIPSO based ESA-EARLINET LIVAS Pure-Dust and Clim-DE products are used to understand the structure of dust aerosol layers over the study domain. The combined use of Pure Dust AOD and Clim-DE products provides the full three-dimensional desert dust aerosols over the Red Sea. 
Figure 8 shows the seasonal spatial patterns of CALIPSO columnar Dust AOD (DAOD) at 532 $\mathrm{nm}$, over the Red Sea and the surrounding areas averaged for December-February (DJF), March-May (MAM), June-August (JJA), and September-November (SON) between 01/2007 and 12/2015. It must be clarified that the seasons have been defined based on the temporal and spatial characteristics of Aeolian dust activity over the Red Sea $[10,63]$. From the geographical distributions of DAOD, it is revealed that the dust activity over the Red Sea peaks in summer, while it diminishes during winter. Moreover, a strong north-to-south and west-to-east DAOD increasing gradient is apparent over the study domain, throughout the year. The maximum DAODs (up to 0.5) are recorded over the southern parts of the Red Sea and Saudi Arabia in summer and spring, respectively. In autumn (SON), DAODs do not exceed 0.3, while in winter (DJF), the minimum DAODs (less than 0.1) throughout the year are observed over the eastern parts of the Sahara Desert.
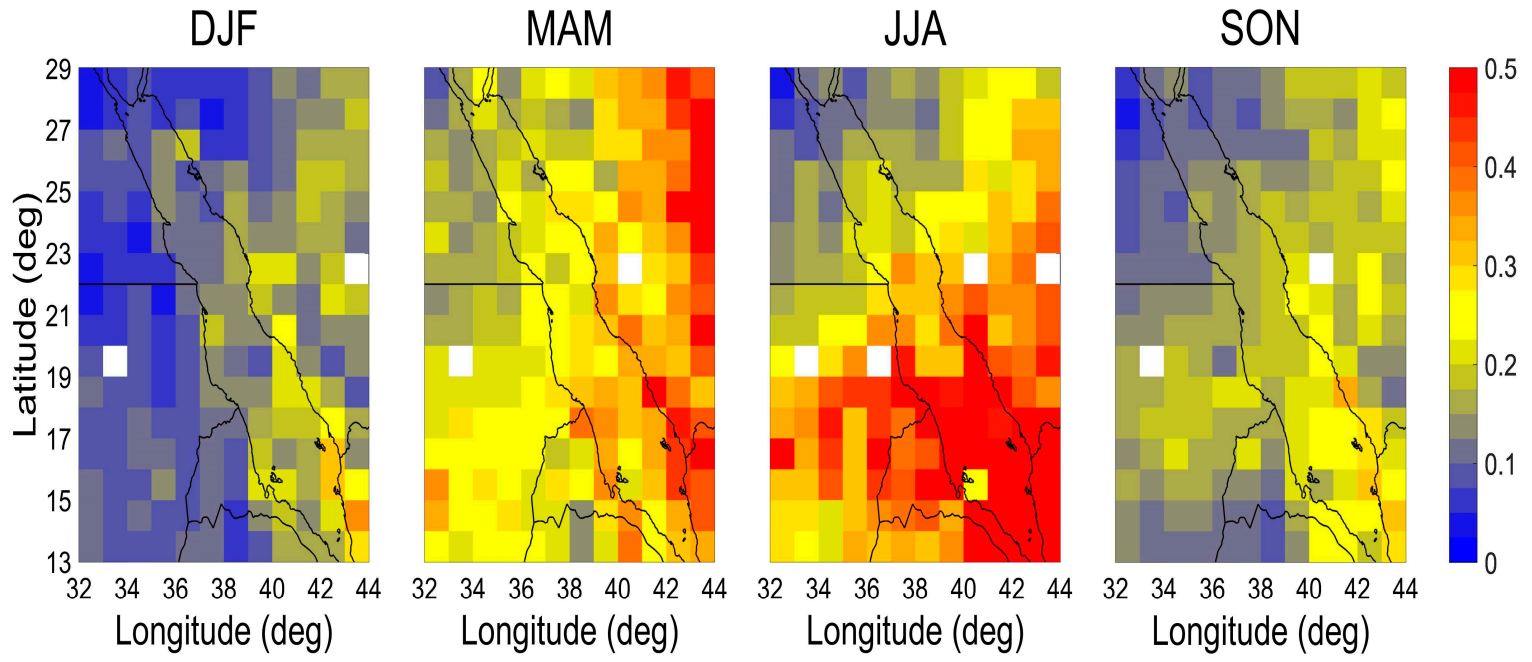

Figure 8. Geographical distribution of the mean Cloud-Aerosol Lidar and Infrared Pathfinder Satellite Observations (CALIPSO) Dust AOD at $532 \mathrm{~nm}$, for the three-month averages: December to February (DJF), from March to May (MAM), from June to August (JJA), and from September to November (SON), for the period 01/2007-12/2015.

In order to illustrate the vertical distribution of dust aerosols over the Red Sea, the seasonal extinction coefficient profiles (Clim-DE), which were averaged over the period 2007-2015, have been produced for each sub region (NRS, NCRS, SCRS, SRS). As indicated in Figure 9, throughout the year, the main portion of dust aerosols is confined in the lowest troposphere (lower than $1 \mathrm{~km}$ ), with maximum Clim-DE values ranging from 0.08 (Figure 9d) to 0.24 (Figure 9o) km ${ }^{-1}$, depending on the sub region. Mean dust extinction coefficient gradually decreases with height, reaching values that are less than $0.01 \mathrm{~km}^{-1}$ up to $6 \mathrm{~km}^{-1}$. Furthermore, elevated dust aerosol layers $(2-5 \mathrm{~km})$ are evident mainly between March and August and for latitudes southern to $20^{\circ} \mathrm{N}$, encompassing the SCRS and SRS regions, while during autumn and winter, dust aerosol layers are in general suppressed below $5 \mathrm{~km}$ height. Among the sub regions, the highest extinction coefficients are found during MAM in the northern domains (NRS and NCRS), while the corresponding values in SCRS and SRS are observed during JJA. The synergistic implementation of the mean DAOD product (Figure 7) and the climatological extinction coefficient profiles (Figure 9) provides an insight regarding the seasonal variation of dust aerosols three-dimensional distribution above the Red Sea. 

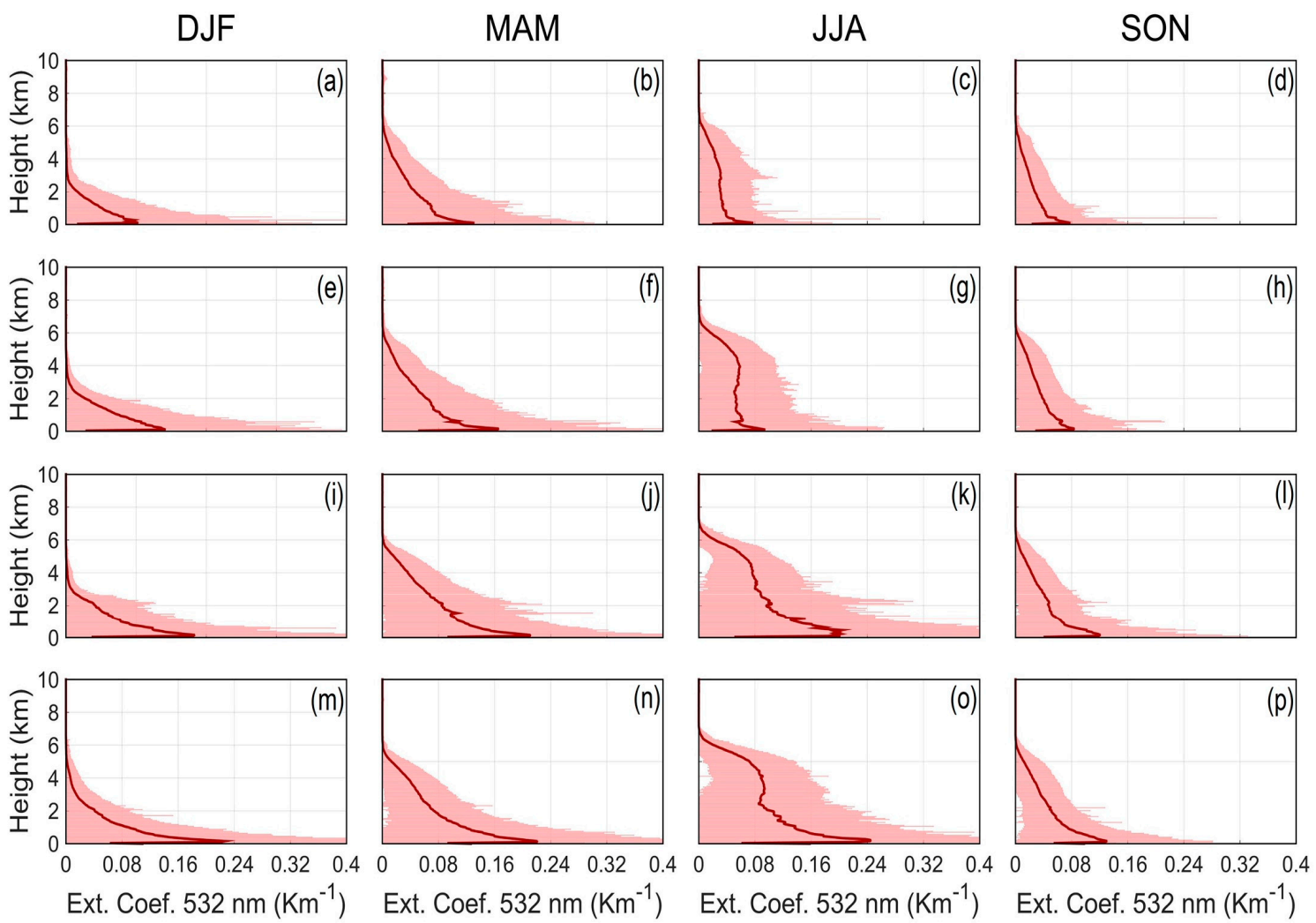

Figure 9. CALIPSO seasonal mean pure dust climatological extinction coefficient profiles at $532 \mathrm{~nm}$ (in $\mathrm{km}^{-1}$ ) for the regions NRS (a-d), NCRS (e-h), SCRS (i-1), SRS ( $\left.\mathbf{m}-\mathbf{p}\right)$, and for the three month averages: December to February (DJF), from March to May (MAM), from June to August (JJA), and from September to November (SON), for the period 01/2007-12/2015.

The strong spatial and temporal variability of DAOD across the study domain is driven by the geographical features as well as on the different meteorological mechanisms favoring dust mobilization and uplifting over arid areas of the eastern Saharan Desert and the Arabian Peninsula [63-65]. Dust generating dynamical processes include meteorological mechanisms of different scales, such as cyclones and anticyclones [66,67], Nocturnal Low-Level Jets [68,69], and Haboobs [70,71]. Between February and April, mid-latitude Mediterranean cyclones associated with cold fronts passages result in a long-range transport of Saharan dust aerosol towards the northern Red Sea [63,72]. By contrast, during summer the major sources of dust aerosols are the Arabian Peninsula deserts (An-Nafud, Ad-Dahna, Rub-Al-Khali) and the local sources of Eritrea and the Republic of Sudan. Under favorable synoptic conditions, dust events take place over the southern Red Sea [63,73]. In addition, the dust aerosol transport and deposition processes are highly dependent on the local topography in the vicinity of the Red Sea. At the northern parts (NRS, NCRS), the less complex surface elevation and the flatter topography allow for the free transport of dust aerosol plumes. On the contrary, in the southern parts of the Red Sea (SCRS, SRS) mountain ridges along both the African and Arabian Peninsula coastlines confine dust aerosol flows creating persistent dust layers for extended periods [16]. The removal processes of dust aerosol particles include both dry and wet deposition [74,75]. Dry deposition (or gravitational settling) is the predominant removal mechanism of mineral particles from the atmosphere in the north Red Sea (NRS, NCRS), while over its southern parts, wet deposition plays a key role [72]. The higher dust aerosol load over the southern part of Red Sea [10] in combination with the predominance of wet removal processes results in an increased dust aerosol deposition and input to the southern parts of the Red Sea with respect to its northern parts. 


\section{Discussion}

In this work, we studied a combination of atmospheric and meteorological factors, including SST, dust deposition (DAOD), and wind activities regulating Red Sea phytoplankton growth using 20 years (1997-2016) observation and reanalysis data. We discovered a bias in the OC-CCI data owed to the data merge from different sensors leading to some inconsistency over different time periods. The systematic high bias values occurred mainly during the service period of MERIS sensor. We presented this issue of inconsistency in the time series variation of Chl- $a$ in Figure 3 and discussed it in Section 3.3. To overcome this problem, we divided the data into three periods: before MERIS (1998-2002), during MERIS (2003-2011), and after MERIS (2012-2016), and compared each time frame with the entire time period (1998-2016). Our results confirmed that except for the central Red Sea during (1998-2002) and for NRS during (2012-2016), the correlation maps of most Red Sea regions match those of the entire time period. This is an important conclusion that supports the validity of using OC-CCI data for the long-term correlative analysis that is the focus of this work. An evident negative relationship between Chl- $a$ and SST anomalies is observed and a major decline in Chl- $a$ is correlated with the warmer waters of 2015 and thereafter. Hence, we argue against previous research [7] proposing that the warmer climate conditions could make the Red Sea ecosystem more productive, since phytoplankton could not get underlying nutrition [76]. The vertical analysis of dust aerosol optical depth proved that DAOD is a reliable indicator of dust deposition over the Red Sea ecosystem. We found that dust deposition contributed at different extents over different regions of the Red Sea to the Chl- $a$ anomalies. This is clear from the positive correlation between DAOD and Chl- $a$ at different lags. It is noteworthy that the SCRS exhibits a two-month lag, thus confirming the impact of the anomalous event during June 2015 [19]. However, not all of the dust events could induce phytoplankton blooms, due to the varying nature of the dust sources. For instance, SRS received more wet deposition as compared to the NRS (see Figure 5), resulting in more bioavailable nutrient (e.g., Fe, Si) for ocean ecosystems. Meanwhile, the positive correlation between wind speed and Chl- $a$ verified that preferred wind patterns could enhance the horizontal intrusion of nutrient-rich water to the southern Red Sea [3]. We found that stronger winds brought more nutritious water from Gulf of Aden into the Red Sea (see SRS in Figure 4(b5-b8)). Furthermore, strong wind also enhanced vertical mixing, thus bringing deeper water that is nutrient rich to be brought into the euphotic zone [3]. This is clear from the positive correlation between Chl- $a$ and wind speed anomalies over the northernmost Red Sea as shown in Figure 4(b8). Ocean circulation is a quite important factor influencing the phytoplankton blooms distribution [3,19]. Hence, it is expected that the inflow of nutrient-rich seawater from the Gulf of Aden can affect most regions of the Red Sea, including NCRS, SCRS, and SRS. Our 19 years analysis showed a similar monthly correlation variability between Chl- $a$ and SST anomalies for the central and southern regions, but not for the NRS, suggesting the role that the inflow played here (See Figure 6a). Moreover, since mesoscale anti-cyclonic eddies affect phytoplankton blooms through transferring nutrients and/or Chl- $a$ to the open waters in the central Red Sea, our cross correlation maps showed the eddies' role, resulting in the October 2002 bloom that wsa reported in Sofianos and Johns [2] (see Figure 4(a2,a6,b2,b6)) and the June 2015 bloom reported in Li et al. [19] (see Figure 7, Chl- $a$ and DAOD anomalies at lag 2). The CALIPSO AOD climatology supported the dust contribution to the Chl- $a$, as discussed above and showed by the positive correlation coefficients (Table 2), since the dust activity peaked during summer and diminished during winter (see Figure 8). The extinction coefficient vertical profiles validated the dust aerosols contribution since the elevated dust layers $(2-5 \mathrm{~km})$ were evident during summer season mainly over the SCRS and SRS regions (see Figure 9).

\section{Conclusions}

This study considers a combination of different factors that are regulating nutrient supply in the Red Sea environment that may contribute to the observed anomalous phytoplankton outbreaks. We found that the Red Sea environment experienced, as expected, a negative correlation between SST and Chl- $a$ observations. This negative correlation is plausible since phytoplankton normally blooms 
during winter. However, we also found that this negative relationship still holds between SST and Chl- $a$ anomalies, with few exceptions that can be attributed to some eddy activities or possible wet dust deposition. It is clear that anomalously cooler water, either from upwelling or intruding current from Gulf of Aden, could bring nutrients leading to enhanced phytoplankton blooming. On the other hand anomalously warmer water experiences reduced phytoplankton blooming because of nutrients shortage that is induced by stronger stratification and reduced mixing layer depth. This is evident from the extremely high SST anomalies paired with extremely low Chl- $a$ anomalies during 2015-2016. Hence, we believe that warmer climate conditions could make the Red Sea ecosystem less productive. The extent of the June, 2010 anomalous event over the entire Red Sea environment made it quite interesting and it was deeply investigated. A combination of factors, ranging from SST anomalies, wet and dry dust deposition, and elevated wind speeds all contributed to the extent of that event. The strong north-to-south, west-to-east increasing gradient of the DAOD explains the higher dust activity on the southern regions of the Red Sea environment during summer and spring seasons that agrees with the higher productivity. This is evident from the correlation maps between Chl- $a$ and DAOD anomalies at specifically two and three months lags over the southern Red Sea yet still with some contributions to the other regions as well at 0 lag. Our multi sensor approach together with the correlative analyses enhanced our understating of varying contributing atmospheric and meteorological factors into the phytoplankton blooms. Further research will be conducted for specific cases of anomalous blooms over the Arabian Gulf to investigate the regional extent of contributing factors to other neighboring water bodies.

Author Contributions: Wenzhao Li implemented the methods, analyzed the data, and provided written sections to the corresponding author for revision and inclusion. Hesham El-Askary led the entire research effort and came up with the idea and plan of work. He was involved in all steps of data rendering, analysis, manuscript writing and revising. Mohamed Qurban provided suggestions and insights about eddies and productivity as well as participating actively in the discussions and manuscript preparation. Emmanouil Proestakis, Vassilis Amiridis, Antonis Gkikas and Eleni Marinou from National Observatory of Athens and University of Patras contributed CALIPSO Dust AOD analysis and pure dust climatological extinction coefficient profiles. Michael Garay performed the time series analysis helped with the lag correlation, OC-CCI data correction and assisted with the writing, particularly the revisions. Olga Kalashnikova provided technical opinions assisted with the Giovanni data collection and time series analysis. Thomas Piechota provided technical opinions to the overall idea and helped in the language editing and writing process. K. P. Manikandan contributed to the field investigation for future cross comparison with satellite observations as well as in the data processing and in the group discussions. All authors read and approved the final manuscript.

Acknowledgments: The authors would like to acknowledge the use of the Samueli Laboratory in Computational Sciences in the Schmid College of Science and Technology, Chapman University for data processing and analysis. Emmanouil Proestakis acknowledges the Stavros Niarchos Foundation for its support. Emmanouil Proestakis and Eleni Marinou acknowledge support through the A. G. Leventis Foundation scholarship, as well as ESA-ESTEC (contract no. 4000104106/11/NL/FF/fk). Antonis Gkikas acknowledges the DUST-GLASS project funded from the European Union's Horizon 2020 research and Innovation programme under the Marie Skłodowska-Curie grant agreement No 749461. We would also like to acknowledge the Center for Environment and Water, King Fahd University of Petroleum and Minerals (KFUPM), Saudi Arabia for conducting field measurements for use in further comparisons and validations studies. Michael Garay and Olga Kalashnikova acknowledge the support of the NASA PACE Science Team program and its manager, Paula Bontempi. The authors would like to acknowledge the communication and cooperation with the OC-CCI team for addressing the issues with Chl- $a$ data. Wenzhao Li would like to acknowledge the help of Yan Yu from Jet Propulsion Laboratory (JPL).

Conflicts of Interest: The authors declare no conflict of interest.

\section{References}

1. Sofianos, S.S.; Johns, W.E. Observations of the summer Red Sea circulation. J. Geophys. Res. $2007,112$. [CrossRef]

2. Acker, J.; Leptoukh, G.; Shen, S.; Zhu, T.; Kempler, S. Remotely-sensed chlorophyll a observations of the northern Red Sea indicate seasonal variability and influence of coastal reefs. J. Mar. Syst. 2008, 69, 191-204. [CrossRef]

3. Raitsos, D.E.; Pradhan, Y.; Brewin, R.J.W.; Stenchikov, G.; Hoteit, I. Remote Sensing the Phytoplankton Seasonal Succession of the Red Sea. PLoS ONE 2013, 8, e64909. [CrossRef] [PubMed] 
4. Qurban, M.A.; Balala, A.C.; Kumar, S.; Bhavya, P.S.; Wafar, M. Primary production in the northern Red Sea. J. Mar. Syst. 2014, 132, 75-82. [CrossRef]

5. Yao, F.; Hoteit, I.; Pratt, L.J.; Bower, A.S.; Zhai, P.; Köhl, A.; Gopalakrishnan, G. Seasonal overturning circulation in the Red Sea: 1. Model validation and summer circulation. J. Geophys. Res. Oceans 2014, 119, 2238-2262. [CrossRef]

6. Churchill, J.H.; Bower, A.S.; McCorkle, D.C.; Abualnaja, Y. The transport of nutrient-rich Indian Ocean water through the Red Sea and into coastal reef systems. J. Mar. Res. 2014, 72, 165-181. [CrossRef]

7. Raitsos, D.E.; Yi, X.; Platt, T.; Racault, M.-F.; Brewin, R.J.W.; Pradhan, Y.; Papadopoulos, V.P.; Sathyendranath, S.; Hoteit, I. Monsoon oscillations regulate fertility of the Red Sea: Monsoons regulate Red Sea greenness. Geophys. Res. Lett. 2015, 42, 855-862. [CrossRef]

8. Racault, M.-F.; Raitsos, D.E.; Berumen, M.L.; Brewin, R.J.W.; Platt, T.; Sathyendranath, S.; Hoteit, I. Phytoplankton phenology indices in coral reef ecosystems: Application to ocean-color observations in the Red Sea. Remote Sens. Environ. 2015, 160, 222-234. [CrossRef]

9. Brewin, R.J.W.; Raitsos, D.E.; Dall'Olmo, G.; Zarokanellos, N.; Jackson, T.; Racault, M.-F.; Boss, E.S.; Sathyendranath, S.; Jones, B.H.; Hoteit, I. Regional ocean-colour chlorophyll algorithms for the Red Sea. Remote Sens. Environ. 2015, 165, 64-85. [CrossRef]

10. Brindley, H.; Osipov, S.; Bantges, R.; Smirnov, A.; Banks, J.; Levy, R.; Jish Prakash, P.; Stenchikov, G. An assessment of the quality of aerosol retrievals over the Red Sea and evaluation of the climatological cloud-free dust direct radiative effect in the region: Aerosol Radiative Effect over Red Sea. J. Geophys. Res. Atmos. 2015, 120, 10862-10878. [CrossRef]

11. Wafar, M.; Ashraf, M.; Manikandan, K.P.; Qurban, M.A.; Kattan, Y. Propagation of Gulf of Aden Intermediate Water (GAIW) in the Red Sea during autumn and its importance to biological production. J. Mar. Syst. 2016, 154, 243-251. [CrossRef]

12. Wafar, M.; Qurban, M.A.; Ashraf, M.; Manikandan, K.P.; Flandez, A.V.; Balala, A.C. Patterns of distribution of inorganic nutrients in Red Sea and their implications to primary production. J. Mar. Syst. 2016, 156, 86-98. [CrossRef]

13. Almahasheer, H.; Duarte, C.M.; Irigoien, X. Nutrient Limitation in Central Red Sea Mangroves. Front. Mar. Sci. 2016, 3, 271. [CrossRef]

14. Dreano, D.; Raitsos, D.E.; Gittings, J.; Krokos, G.; Hoteit, I. The Gulf of Aden Intermediate Water Intrusion Regulates the Southern Red Sea Summer Phytoplankton Blooms. PLoS ONE 2016, 11, e0168440. [CrossRef] [PubMed]

15. Eladawy, A.; Nadaoka, K.; Negm, A.; Abdel-Fattah, S.; Hanafy, M.; Shaltout, M. Characterization of the northern Red Sea's oceanic features with remote sensing data and outputs from a global circulation model. Oceanologia 2017, 59, 213-237. [CrossRef]

16. Banks, J.R.; Brindley, H.E.; Stenchikov, G.; Schepanski, K. Satellite retrievals of dust aerosol over the Red Sea and the Persian Gulf (2005-2015). Atmos. Chem. Phys. 2017, 17, 3987-4003. [CrossRef]

17. Qurban, M.A.; Wafar, M.; Jyothibabu, R.; Manikandan, K.P. Patterns of primary production in the Red Sea. J. Mar. Syst. 2017, 169, 87-98. [CrossRef]

18. Racault, M.-F.; Sathyendranath, S.; Brewin, R.J.W.; Raitsos, D.E.; Jackson, T.; Platt, T. Impact of El Niño Variability on Oceanic Phytoplankton. Front. Mar. Sci. 2017, 4, 133. [CrossRef]

19. Li, W.; El-Askary, H.; ManiKandan, K.; Qurban, M.; Garay, M.; Kalashnikova, O. Synergistic Use of Remote Sensing and Modeling to Assess an Anomalously High Chlorophyll-a Event during Summer 2015 in the South Central Red Sea. Remote Sens. 2017, 9, 778. [CrossRef]

20. Shaikh, E.A.; Roff, J.C.; Dowidar, N.M. Phytoplankton ecology and production in the Red Sea off Jiddah, Saudi Arabia. Mar. Biol. 1986, 92, 405-416. [CrossRef]

21. International Association for the Physical Sciences of the Ocean. An outline of the weather and climate of the Red Sea. In Physical Oceanography of the Red Sea: Symposium of the International Association of Physical Sciences of the Ocean; Documentation Service, Saclay Nuclear Research Center, University of California: Oakland, CA, USA, 1974; pp. 9-27.

22. Grasshoff, K. The hydrochemistry of landlocked basins and fjords. Chem. Oceanogr. 1975, 2, $455-597$.

23. Froese, R.; Pauly, D. (Eds.) World Wide Web Electronic Publication, wwww.fishbase.org, Version (02/2017); FishBase: Los Banos, CA, USA, 2017. 
24. Price, A.R.G.; Ghazi, S.J.; Tkaczynski, P.J.; Venkatachalam, A.J.; Santillan, A.; Pancho, T.; Metcalfe, R.; Saunders, J. Shifting environmental baselines in the Red Sea. Mar. Pollut. Bull. 2014, 78, 96-101. [CrossRef] [PubMed]

25. Transboundary Water Assessment Programme. LME 33-Red Sea; Transboundary Water Assessment Programme: Nairobi, Kenya, 2015.

26. Cantin, N.E.; Cohen, A.L.; Karnauskas, K.B.; Tarrant, A.M.; McCorkle, D.C. Ocean Warming Slows Coral Growth in the Central Red Sea. Science 2010, 329, 322-325. [CrossRef] [PubMed]

27. Berumen, M.L.; Hoey, A.S.; Bass, W.H.; Bouwmeester, J.; Catania, D.; Cochran, J.E.M.; Khalil, M.T.; Miyake, S.; Mughal, M.R.; Spaet, J.L.Y.; et al. The status of coral reef ecology research in the Red Sea. Coral Reefs 2013, 32, 737-748. [CrossRef]

28. Raitsos, D.E.; Brewin, R.J.W.; Zhan, P.; Dreano, D.; Pradhan, Y.; Nanninga, G.B.; Hoteit, I. Sensing coral reef connectivity pathways from space. Sci. Rep. 2017, 7. [CrossRef] [PubMed]

29. Jickells, T.D. Global Iron Connections Between Desert Dust, Ocean Biogeochemistry, and Climate. Science 2005, 308, 67-71. [CrossRef] [PubMed]

30. Brewin, R.J.W.; Raitsos, D.E.; Pradhan, Y.; Hoteit, I. Comparison of chlorophyll in the Red Sea derived from MODIS-Aqua and in vivo fluorescence. Remote Sens. Environ. 2013, 136, 218-224. [CrossRef]

31. Mélin, F.; Vantrepotte, V.; Chuprin, A.; Grant, M.; Jackson, T.; Sathyendranath, S. Assessing the fitness-for-purpose of satellite multi-mission ocean color climate data records: A protocol applied to OC-CCI chlorophyll- $a$ data. Remote Sens. Environ. 2017, 203, 139-151. [CrossRef] [PubMed]

32. Mélin, F.; Sclep, G. Band shifting for ocean color multi-spectral reflectance data. Opt. Express 2015, $23,2262$. [CrossRef] [PubMed]

33. Sathyendranath, S.; Brewin, R.J.W.; Jackson, T.; Mélin, F.; Platt, T. Ocean-colour products for climate-change studies: What are their ideal characteristics? Remote Sens. Environ. 2017, 203, 125-138. [CrossRef]

34. Jackson, T.; Sathyendranath, S.; Mélin, F. An improved optical classification scheme for the Ocean Colour Essential Climate Variable and its applications. Remote Sens. Environ. 2017, 203, 152-161. [CrossRef]

35. Brewin, R.J.W.; Ciavatta, S.; Sathyendranath, S.; Jackson, T.; Tilstone, G.; Curran, K.; Airs, R.L.; Cummings, D.; Brotas, V.; Organelli, E.; et al. Uncertainty in Ocean-Color Estimates of Chlorophyll for Phytoplankton Groups. Front. Mar. Sci. 2017, 4, 104. [CrossRef]

36. Evers-King, H.; Martinez-Vicente, V.; Brewin, R.J.W.; Dall'Olmo, G.; Hickman, A.E.; Jackson, T.; Kostadinov, T.S.; Krasemann, H.; Loisel, H.; Röttgers, R.; et al. Validation and Intercomparison of Ocean Color Algorithms for Estimating Particulate Organic Carbon in the Oceans. Front. Mar. Sci. 2017, 4, 251. [CrossRef]

37. Ocean Biology Processing Group. MODIS Aqua Level 3 SST Thermal IR Monthly 4 km Daytime v2014.0; PO.DAAC: Pasadena, CA, USA, 2015.

38. National Oceanographic Data Center and Rosen Rosenstiel School of Marine and Atmospheric Science. AVHRR Pathfinder Level 3 Monthly Daytime SST Version 5; PO.DAAC: Pasadena, CA, USA, 2003.

39. Kilpatrick, K.A.; Podestá, G.P.; Evans, R. Overview of the NOAA/NASA advanced very high resolution radiometer Pathfinder algorithm for sea surface temperature and associated matchup database. J. Geophys. Res. Oceans 2001, 106, 9179-9197. [CrossRef]

40. Berrick, S.W.; Leptoukh, G.; Farley, J.D.; Rui, H. Giovanni: A Web Service Workflow-Based Data Visualization and Analysis System. IEEE Trans. Geosci. Remote Sens. 2009, 47, 106-113. [CrossRef]

41. Global Modeling and Assimilation Office. MERRA-2 tavgM_2d_adg_Nx: 2d, Monthly Mean, Time-Averaged, Single-Level, Assimilation, Aerosol Diagnostics (Extended) V5.12.4; Goddard Earth Sciences Data and Information Services Center (GES DISC): Greenbelt, MD, USA, 2015.

42. Global Modeling and Assimilation Office. MERRA-2 tavgM_2d_aer_Nx: 2d, Monthly Mean, Time-Averaged, Single-Level, Assimilation, Aerosol Diagnostics V5.12.4; Goddard Earth Sciences Data and Information Services Center (GES DISC): Greenbelt, MD, USA, 2015.

43. Diner, D. MISR Level 3 Component Global Aerosol Product Covering a Month HDF-EOS File_Version 4; NASA Langley Atmospheric Science Data Center (DAAC): Hampton, VA, USA, 2009. [CrossRef]

44. Abdou, W.A. Comparison of coincident Multiangle Imaging Spectroradiometer and Moderate Resolution Imaging Spectroradiometer aerosol optical depths over land and ocean scenes containing Aerosol Robotic Network sites. J. Geophys. Res. 2005, 110. [CrossRef] 
45. Marey, H.S.; Gille, J.C.; El-Askary, H.M.; Shalaby, E.A.; El-Raey, M.E. Study of the formation of the "Black Cloud" and its dynamics over Cairo, Egypt using MODIS and MISR sensors. J. Geophys. Res. 2010, 115. [CrossRef]

46. Winker, D.M.; Hunt, W.H.; McGill, M.J. Initial performance assessment of CALIOP. Geophys. Res. Lett. $2007,34$. [CrossRef]

47. Hunt, W.H.; Winker, D.M.; Vaughan, M.A.; Powell, K.A.; Lucker, P.L.; Weimer, C. CALIPSO Lidar Description and Performance Assessment. J. Atmos. Ocean. Technol. 2009, 26, 1214-1228. [CrossRef]

48. Winker, D.M.; Vaughan, M.A.; Omar, A.; Hu, Y.; Powell, K.A.; Liu, Z.; Hunt, W.H.; Young, S.A. Overview of the CALIPSO Mission and CALIOP Data Processing Algorithms. J. Atmos. Ocean. Technol. 2009, 26, 2310-2323. [CrossRef]

49. Omar, A.H.; Winker, D.M.; Vaughan, M.A.; Hu, Y.; Trepte, C.R.; Ferrare, R.A.; Lee, K.-P.; Hostetler, C.A.; Kittaka, C.; Rogers, R.R.; et al. The CALIPSO Automated Aerosol Classification and Lidar Ratio Selection Algorithm. J. Atmos. Ocean. Technol. 2009, 26, 1994-2014. [CrossRef]

50. Young, S.A.; Vaughan, M.A. The Retrieval of Profiles of Particulate Extinction from Cloud-Aerosol Lidar Infrared Pathfinder Satellite Observations (CALIPSO) Data: Algorithm Description. J. Atmos. Ocean. Technol. 2009, 26, 1105-1119. [CrossRef]

51. Ansmann, A.; Bösenberg, J.; Chaikovsky, A.; Comerón, A.; Eckhardt, S.; Eixmann, R.; Freudenthaler, V.; Ginoux, P.; Komguem, L.; Linné, H.; et al. Long-range transport of Saharan dust to northern Europe: The 11-16 October 2001 outbreak observed with EARLINET: SAHARAN DUST TRANSPORT OVER EUROPE. J. Geophys. Res. Atmos. 2003, 108. [CrossRef]

52. Balis, D.S.; Amiridis, V.; Nickovic, S.; Papayannis, A.; Zerefos, C. Optical properties of Saharan dust layers as detected by a Raman lidar at Thessaloniki, Greece: Optical Properties of Dust Layers at Thessaloniki. Geophys. Res. Lett. 2004, 31. [CrossRef]

53. Mona, L.; Liu, Z.; Müller, D.; Omar, A.; Papayannis, A.; Pappalardo, G.; Sugimoto, N.; Vaughan, M. Lidar Measurements for Desert Dust Characterization: An Overview. Adv. Meteorol. 2012, 2012, 1-36. [CrossRef]

54. Amiridis, V.; Wandinger, U.; Marinou, E.; Giannakaki, E.; Tsekeri, A.; Basart, S.; Kazadzis, S.; Gkikas, A.; Taylor, M.; Baldasano, J.; et al. Optimizing CALIPSO Saharan dust retrievals. Atmos. Chem. Phys. 2013, 13, 12089-12106. [CrossRef]

55. Liu, Z.; Omar, A.; Vaughan, M.; Hair, J.; Kittaka, C.; Hu, Y.; Powell, K.; Trepte, C.; Winker, D.; Hostetler, C.; et al. CALIPSO lidar observations of the optical properties of Saharan dust: A case study of long-range transport. J. Geophys. Res. 2008, 113. [CrossRef]

56. Tesche, M.; Ansmann, A.; Müller, D.; Althausen, D.; Engelmann, R.; Freudenthaler, V.; Groß, S. Vertically resolved separation of dust and smoke over Cape Verde using multiwavelength Raman and polarization lidars during Saharan Mineral Dust Experiment 2008. J. Geophys. Res. 2009, 114. [CrossRef]

57. Amiridis, V.; Marinou, E.; Tsekeri, A.; Wandinger, U.; Schwarz, A.; Giannakaki, E.; Mamouri, R.; Kokkalis, P.; Binietoglou, I.; Solomos, S.; et al. LIVAS: A 3-D multi-wavelength aerosol/cloud database based on CALIPSO and EARLINET. Atmos. Chem. Phys. 2015, 15, 7127-7153. [CrossRef]

58. Marinou, E.; Amiridis, V.; Binietoglou, I.; Tsikerdekis, A.; Solomos, S.; Proestakis, E.; Konsta, D.; Papagiannopoulos, N.; Tsekeri, A.; Vlastou, G.; et al. Three-dimensional evolution of Saharan dust transport towards Europe based on a 9-year EARLINET-optimized CALIPSO dataset. Atmos. Chem. Phys. 2017, 17, 5893-5919. [CrossRef]

59. Proestakis, E.; Amiridis, V.; Marinou, E.; Georgoulias, A.K.; Solomos, S.; Kazadzis, S.; Chimot, J.; Che, H.; Alexandri, G.; Binietoglou, I.; et al. 9-year spatial and temporal evolution of desert dust aerosols over South-East Asia as revealed by CALIOP. Atmos. Chem. Phys. Discuss. 2017, 18, 1337. [CrossRef]

60. Schulz, M.; Prospero, J.M.; Baker, A.R.; Dentener, F.; Ickes, L.; Liss, P.S.; Mahowald, N.M.; Nickovic, S.; García-Pando, C.P.; Rodríguez, S.; et al. Atmospheric Transport and Deposition of Mineral Dust to the Ocean: Implications for Research Needs. Environ. Sci. Technol. 2012, 46, 10390-10404. [CrossRef] [PubMed]

61. Mahowald, N.M.; Baker, A.R.; Bergametti, G.; Brooks, N.; Duce, R.A.; Jickells, T.D.; Kubilay, N.; Prospero, J.M.; Tegen, I. Atmospheric global dust cycle and iron inputs to the ocean: ATMOSPHERIC IRON DEPOSITION. Glob. Biogeochem. Cycles 2005, 19. [CrossRef]

62. WMO Statement on the State of the Global Climate in 2017. Available online: https://public.wmo.int/en/ wmo-statement-state-of-global-climate-2017 (accessed on 18 January 2018).

63. Notaro, M.; Alkolibi, F.; Fadda, E.; Bakhrjy, F. Trajectory analysis of Saudi Arabian dust storms: SAUDI ARABIAN DUST STORMS. J. Geophys. Res. Atmos. 2013, 118, 6028-6043. [CrossRef] 
64. Ginoux, P.; Prospero, J.M.; Gill, T.E.; Hsu, N.C.; Zhao, M. Global-scale attribution of anthropogenic and natural dust sources and their emission rates based on MODIS Deep Blue aerosol products: Anthropogenic and Natural Dust Sources. Rev. Geophys. 2012, 50. [CrossRef]

65. Prospero, J.M. Environmental characterization of global sources of atmospheric soil dust identified with the NIMBUS 7 Total Ozone Mapping Spectrometer (TOMS) absorbing aerosol product. Rev. Geophys. 2002, 40. [CrossRef]

66. Fiedler, S.; Schepanski, K.; Knippertz, P.; Heinold, B.; Tegen, I. How important are atmospheric depressions and mobile cyclones for emitting mineral dust aerosol in North Africa? Atmos. Chem. Phys. 2014, 14, 8983-9000. [CrossRef]

67. Marsham, J.H.; Parker, D.J.; Grams, C.M.; Taylor, C.M.; Haywood, J.M. Uplift of Saharan dust south of the intertropical discontinuity. J. Geophys. Res. 2008, 113. [CrossRef]

68. Knippertz, P. Dust emissions in the West African heat trough the role of the diurnal cycle and of extratropical disturbances. Meteorol. Z. 2008, 17, 553-563. [CrossRef]

69. Schepanski, K.; Tegen, I.; Todd, M.C.; Heinold, B.; Bönisch, G.; Laurent, B.; Macke, A. Meteorological processes forcing Saharan dust emission inferred from MSG-SEVIRI observations of subdaily dust source activation and numerical models. J. Geophys. Res. 2009, 114. [CrossRef]

70. Roberts, A.J.; Knippertz, P. The formation of a large summertime Saharan dust plume: Convective and synoptic-scale analysis. J. Geophys. Res. Atmos. 2014, 119, 1766-1785. [CrossRef] [PubMed]

71. Solomos, S.; Kallos, G.; Mavromatidis, E.; Kushta, J. Density currents as a desert dust mobilization mechanism. Atmos. Chem. Phys. 2012, 12, 11199-11211. [CrossRef]

72. Kalenderski, S.; Stenchikov, G. High-resolution regional modeling of summertime transport and impact of African dust over the Red Sea and Arabian Peninsula: High-Resolution Regional Modeling. J. Geophys. Res. Atmos. 2016, 121, 6435-6458. [CrossRef]

73. Jish Prakash, P.; Stenchikov, G.; Kalenderski, S.; Osipov, S.; Bangalath, H. The impact of dust storms on the Arabian Peninsula and the Red Sea. Atmos. Chem. Phys. 2015, 15, 199-222. [CrossRef]

74. Duce, R.A.; Liss, P.S.; Merrill, J.T.; Atlas, E.L.; Buat-Menard, P.; Hicks, B.B.; Miller, J.M.; Prospero, J.M.; Arimoto, R.; Church, T.M.; et al. The atmospheric input of trace species to the world ocean. Glob. Biogeochem. Cycles 1991, 5 , 193-259. [CrossRef]

75. Pryor, S.C.; Gallagher, M.; Sievering, H.; Larsen, S.E.; Barthelmie, R.J.; Birsan, F.; Nemitz, E.; Rinne, J.; Kulmala, M.; Grönholm, T.; et al. A review of measurement and modelling results of particle atmosphere-surface exchange. Tellus B Chem. Phys. Meteorol. 2008, 60, 42-75. [CrossRef]

76. Gittings, J.A.; Raitsos, D.E.; Krokos, G.; Hoteit, I. Impacts of warming on phytoplankton abundance and phenology in a typical tropical marine ecosystem. Sci. Rep. 2018, 8, 2240. [CrossRef] [PubMed] 